\title{
A comprehensive analysis of the effects of offshore oil and gas exploration and production on the benthic communities of the Norwegian continental shelf
}

\author{
Frode Olsgard, John S. Gray \\ Section of Marine Zoology and Marine Chemistry, Department of Biology, University of Oslo, PO Box 1064 , \\ N-0316 Oslo, Norway
}

\begin{abstract}
Multivariate statistical analyses of data on environmental variables and benthic fauna from 14 oil and gas fields obtained from 24 surveys collected between 1985 and 1993 are presented. At all fields oil-based drilling mud was used. The purpose of this study was to investigate contamination gradients, assess effects on benthic fauna both spatially and temporally and to evaluate measures such as diversity indices, indicator species and multivariate analysis techniques in assessment of pollution. Results from analyses of baseline surveys of environmental variables and fauna were characterised by a lack of distinct gradients in station placement, having a typical shot-gun pattern in PCA-, DCA- and MDS-ordination analyses. Likewise there was no consistency in which environmental variables correlated with the fauna. Contamination was assessed using all the physical and chemical data in classification and PCA-ordination analyses. Clear patterns were found using 4 categories, conveniently termed initial moderate, severe and gross. The categories were usually apparent as rings radiating from the platform. Initial contamination of the outermost areas at most fields was shown as elevated levels of barium and total hydrocarbons (THC) and sometimes also by elevated levels of zinc, copper, cadmium and lead. Three fields were studied in particular and showed contaminated areas of over $100 \mathrm{~km}^{2}$ (Valhall), over $15 \mathrm{~km}^{2}$ (Gyda) and over $10 \mathrm{~km}^{2}$ (Veslefrikk). After a period of 6 to $9 \mathrm{yr}$ contamination had spread, so that nearly all of the outermost stations 2 to $6 \mathrm{~km}$ away from the platforms showed evidence of contamination. Thus, the existing sampling design is no longer suitable for assessment of the area contaminated. Effects on the fauna showed, as with contamination, 4 categories. Analyses linking fauna and environmental variables indicated that the effects were mainly related to THC, barium and strontium, but also to metals like zinc, copper, cadmium and lead, which are all discharged in drill-cuttings. Effects on the fauna closely followed the patterns of contamination with only a few stations at each field that were contaminated not showing effects. Thus the areas showing effects were only slightly less than the areas contaminated. Subsequent to cessation of discharges biodegradation of oil and reduced concentrations of THC were observed. Yet there was an extension of areas where the fauna was affected several years after cessation of drill-cutting discharges. This may indicate that barite and related compounds associated with the discharges also have an environmental impact. However, preliminary results from fields using only water-based mud clearly indicate a reduction in environmental contamination and biological impact, compared to effects reported here, for oil-based drill-cuttings. Diversity indices applied to the data did not show the extent of effects and such indices alone should not be used to interpret changes. The consistent patterns that the multivariate techniques were able to detect showed that these methods were far superior. Analyses of the initial effects on the fauna showed that there were no consistent patterns in changes in species composition over fields or time, and thus the search for 'universal' sensitive indicator species does not seem to be rewarding. Yet under gross effects of pollution there were consistent patterns with the same species dominating Finally, the initial effects of pollution included severe reductions in organisms that are key components of the benthic communities and also food for bottom-living fish, and are thus ecologically important. The new fauna which establishes in the contaminated sediments close to platforms, often with high abundance, will probably be less valuable as a food source for fish populations since it is of small size and lives sub-surface.
\end{abstract}

KEY WORDS: Macrobenthos - Multivariate analyses - Norway · Offshore $\cdot$ Oil drilling 


\section{INTRODUCTION}

Oil and gas reserves in the North Sea have been exploited since the mid $1960 \mathrm{~s}$. It is of wide general interest to obtain an overview of the extent to which these activities affect marine life. Davies \& Kingston (1992) and Kingston (1992) have recently given reviews of effects of oil production on the benthos of the North Sea. Kingston (1992) records that in the early days of exploration it was generally believed that the major input of oil would be in water from platform drainage and production. This was found to be incorrect and the greatest source of oil until now has been in discharged drill-cuttings, which are disposed of during drilling operations (Kingston 1992).

Originally the drill-cuttings were in aqueous solution, but later oil replaced the water as it was preferable in the drilling process. However, due to observed toxic effects of oil-based drilling muds there has been a change in recent years back to water-based muds. Although the composition of drilling muds used varies from area to area, all have a weighting agent, usually barite $\left(\mathrm{BaSO}_{4}\right)$, viscosity agents such as bentonitic clays, swelling controllers (potassium chloride, $\mathrm{KCl}$ ), $\mathrm{pH}$ controllers (potassium hydroxide, $\mathrm{KOH}$ ), filter loss components, dispersants, defoamers, drilling lubricants (such as fatty acids and hydrocarbons), gypsum to increase the calcium content and biocides (GESAMP 1993). Of these chemicals barite is used in large quantities, a typical figure being $1500 \mathrm{t}$ per well, and around $90 \%$ of this is typically discharged after use. The barite contains impurities such as heavy metals and the concentration of such metals discharged depends on the quality of the barite. Since barite is insoluble and has high density it settles at the seabed and thus is often a good tracer for the dispersion of drill-cuttings. The effects of drill-cuttings are therefore likely to be on sediment-living benthos. As a consequence monitoring has focused on identifying changes in sediment contamination and effects of this contamination on the structure of communities living in the sediment. From the foregoing it is clear that drill-cuttings will cause a variety of effects through smothering, toxic chemicals such as heavy metals and hydrocarbons and organic enrichment. The relative importance of the different components will vary from field to field.

All countries producing oil require that monitoring be done to assess the effects on the marine environment. From published information Davies et al. (1981) showed for the UK sector of the North Sea that 'significant contamination was found only in the sediments close to some platforms'. For example Davies \& Kingston (1992) showed that for the Shetland Basin, North Sea, total oil concentrations at distances between 5000 and $10000 \mathrm{~m}$ from platforms had risen from $3-90 \mathrm{ppm}$. in 1979 to $80-900 \mathrm{ppm}$ in 1988. Kingston (1992) reported that for the North Sea typical patterns were concentrations of hydrocarbons between 1000 and 10000 times background close to platforms, with a steep downward gradient between 500 and $1000 \mathrm{~m}$. GESAMP (1993), reporting data from Davies et al. (1989) and unpublished Norwegian data, showed that hydrocarbons were present in elevated concentrations in ellipses of $4000 \times 8000 \mathrm{~m}$ in the UK sector and $5000 \times$ 10-12000 $\mathrm{m}$ in the Norwegian sector. The contamination mentioned above was based on only 1 variable, usually hydrocarbon content of sediments, or at most a few of the wide range of environmental variables regularly monitored. In this paper we apply multivariate analyses to a range of environmental data in order to assess the totality of contamination rather than using merely 1 variable.

Effects of contamination by drill-cuttings were listed by GESAMP (1993) as major to a radius of $500 \mathrm{~m}$ from production platforms in the UK sector and to a $1000 \mathrm{~m}$ radius in the Norwegian sector, with subtle biological effects reaching to a $2000 \times 1000 \mathrm{~m}$ ellipse in the UK sector and a 3000 to $5000 \mathrm{~m}$ radius in the Norwegian sector. Major effects are usually recorded as changes in diversity indices (Addy et al. 1984, Davies et al. 1984, 1989, Dicks et al. 1987, Mair et al. 1987, Kingston 1992). Yet Kingston (1992) showed that although reductions in diversity were found between 750 and $1500 \mathrm{~m}$, using indicator species effects of contaminants can be found between 1500 and $3000 \mathrm{~m}$. In applying multivariate analyses to benthic data from Ekofisk in 1987. Gray et al. (1990) were able to show clear effects out to a radius of $3000 \mathrm{~m}$ from the Ekofisk centre. Kingston (1992) claimed that the full potential of such approaches is not exploited'. The present paper addresses this issue.

Apart from the above there are surprisingly few findings published in the open scientific literature on the effects of oil from platform operations. Most of the data on effects remain confidential to the respective country's environmental authorities. Fortunately, Norway has an open policy and all data reported to the Norwegian State Pollution Control Authority (Statens Forurensningstilsyn, SFT) are open to public scrutiny. Monitoring in the Norwegian sector began in 1973 at Ekofisk and a thorough analysis of the Ekofisk and Eldfisk fields was done by Gray et al. (1990). Exploration has been moving gradually northwards with the result that the oldest fields are found in the south (Ekofisk) and the newest production fields are to be found just outside the Arctic Circle (Heidrun). At present trial drilling is taking place within the Barents Sea.

All companies involved with oil and gas exploration on the Norwegian shelf are required to monitor the 
chemistry of the field annually and do biological surveys every $3 \mathrm{yr}$ for fields with oil production and every 6 yr for fields with gas production. Table 1 shows the monitoring programme initiated in Norway up to 1991. We also have access to more recent surveys and have used some of these in our study as wrell.

Although the drilling activity hos remained fairly high, and has in fact increased in recent years, the amounts of oil and oil-based drill-utings discharged have decreased markedly, haking peaked in 1985 (Fig. 1) (Anon 1994). This is mainly due to legislation imposed by the Norwegian Statte Pollution Control Authority in response to findingsi of reduced faunal diversity $5 \mathrm{~km}$ away from the 5 tatfjord $\mathrm{C}$ platform (Reiersen et al. 1989), and effects ond to $3 \mathrm{~km}$ at Ekofisk and other fields (Gray et al. 1990). In 1987 the amount of oil in cuttings allowed to be djscharged was reduced to a maximum of $6 \%$, and from 1 Jamuary 1993 all discharge of oil-based mud cuttings in the Norwegian sector was banned. Water-based mud is at present the dominant drilling-fluid, and this will often lead to a 5 - to 10 -fold increase in the amount of barite used compared to that used with oil-based mud. Water-based cuttings are more fine grained and can be expected to lead to a wider dispersion of the bicrite.

We have analysed all the data sets on sediment variables and benthic communities. ffrmom the Norwegian continental shelf available up to 1.990 and some sets from 1990 to 1993. In this paper wescribe analyses
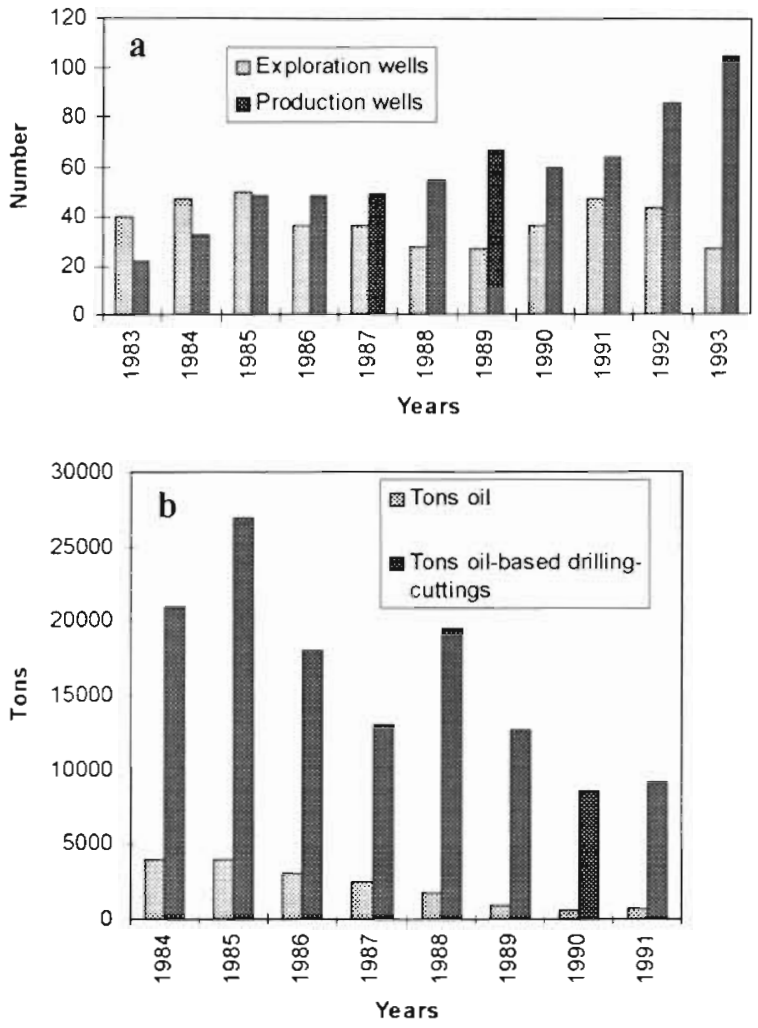

Fig. 1 (a) Number of wells drilled on the Norwegian continental shelf (Anon 1994) and (b) discharges of oil and oilbased drilling-cuttings to the Norwegian continental shelf (Bakke et al. 1993)

Table 1. Oil monitoring on the Norwegian Shelf, 1973 to 1991. C: chemical monitoring; B: biological monitoring; F: fish monitoring:-: no monitoring

\begin{tabular}{|c|c|c|c|c|c|c|c|c|c|c|c|c|c|c|c|}
\hline Field & $1973-77$ & 1978 & 1979 & 1960 & 1981 & 1982 & 1983 & 1984 & 1985 & 1986 & 1987 & 1988 & 1989 & 1990 & 1991 \\
\hline Ekofisk & $C B$ & $\mathrm{CB}$ & $\mathrm{CB}$ & $a$ & $\mathrm{CB}$ & $\mathrm{CB}$ & $\mathrm{C}$ & $\mathrm{CB}$ & $\mathrm{CF}$ & - & $\mathrm{CB}$ & - & - & $\mathrm{CBF}$ & $\mathrm{CB}$ \\
\hline Statfjord & & $\mathrm{C}$ & C & $\mathrm{CEF}$ & $\mathrm{C}$ & $C B$ & $\mathrm{~F}$ & $\mathrm{CB}$ & $\mathrm{C}$ & $\mathrm{CBF}$ & $\mathrm{C}$ & $\mathrm{CB}$ & $\mathrm{C}$ & $\mathrm{CB}$ & $\mathrm{CB}$ \\
\hline Frigg & & & & $E$ & - & - & C & - & - & - & $\mathrm{CBF}$ & - & - & - & $\mathrm{CB}$ \\
\hline Valhall & & & & $c$ & C & C & C & c & $\mathrm{CBF}$ & $\mathrm{CF}$ & $C$ & $\mathrm{CB}$ & C & C & $\mathrm{CB}$ \\
\hline Hod & & & & & & c & C & C & C & $C$ & C & $\mathrm{CB}$ & - & - & $\mathrm{CB}$ \\
\hline Træna Bank & & & & & & $\mathrm{CB}$ & - & $\mathrm{CB}$ & - & - & - & - & - & - & - \\
\hline Oseberg & & & & & & & $\mathrm{CB}$ & - & - & $\mathrm{CBF}$ & C & C & $\mathrm{CB}$ & C & $\mathrm{C}$ \\
\hline Odin & & & & & & & $c$ & C & $\mathrm{CBF}$ & - & - & - & - & - & $\mathrm{CB}$ \\
\hline Ula & & & & & & & & $\mathrm{CB}$ & - & - & $\mathrm{C}$ & $\mathrm{C}$ & $\mathrm{CBF}$ & C & $C B$ \\
\hline Heimdal & & & & & & & & & $c$ & - & $\mathrm{CBF}$ & - & - & - & - \\
\hline Halten Bank & & & & & & & & & $\mathrm{CB}$ & - & - & - & - & - & - \\
\hline Gullfaks & & & & & & & & & $\mathrm{CB}$ & $\mathrm{CB}$ & $\mathrm{C}$ & $\mathrm{CB}$ & $C B$ & $\mathrm{CB}$ & C \\
\hline Veslefrikk & & & & & & & & & & & $\mathrm{CB}$ & $\mathrm{C}$ & $\mathrm{C}$ & $\mathrm{CB}$ & $\mathrm{C}$ \\
\hline Gyda & & & & & & & & & & & $\mathrm{CB}$ & C & C & $\mathrm{CB}$ & $C B$ \\
\hline Tommeliten & & & & & & & & & & & $C B$ & - & $\mathrm{CB}$ & - & - \\
\hline Heidrun & & & & & & & & & & & & $\mathrm{CB}$ & - & - & - \\
\hline Snorre & & & & & & & & & & & & & $\mathrm{CB}$ & - & $C B$ \\
\hline Troll Vest I & & & & & & & & & & & & & $\mathrm{CB}$ & C & - \\
\hline TOGI & & & & & & & & & & & & & $\mathrm{CB}$ & $\mathrm{C}$ & - \\
\hline Troll Vest II & & & & & & & & & & & & & & $\mathrm{CB}$ & $\mathrm{CB}$ \\
\hline Mime & & & & & & & & & & & & & & $\mathrm{CB}$ & $\mathrm{CB}$ \\
\hline Brage & & & & & & & & & & & & & & $\mathrm{CB}$ & - \\
\hline Well $2 / 7-22$ & & & & & & & & & & & & & & $\mathrm{CB}$ & C \\
\hline
\end{tabular}




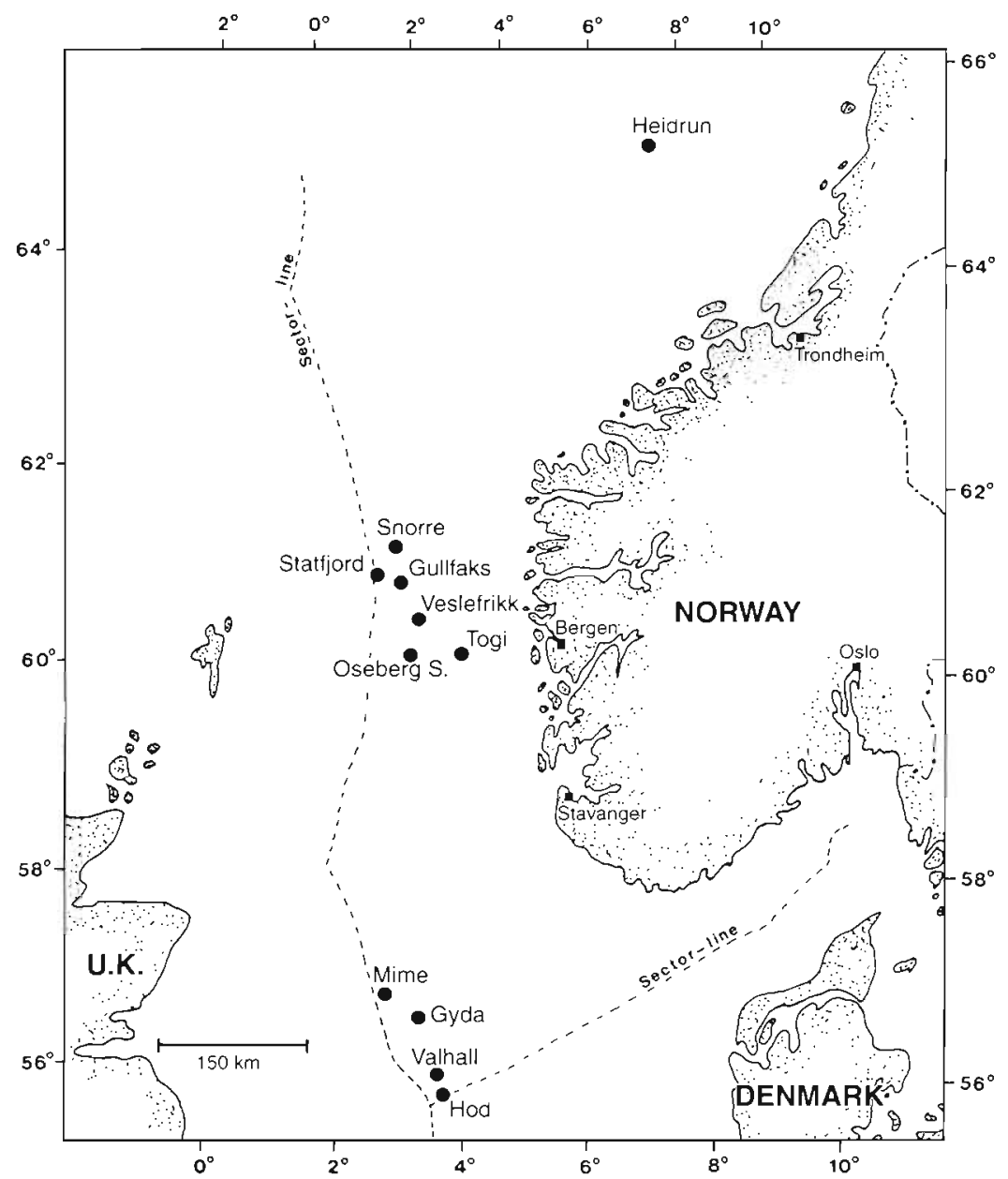

Fig. 2. Location of oil and gas fields sampled

of selected fields between 1985 and 1993. The fields have been selected in part to cover the main areas of activities, in part where data for time series analysis were available and in part because of high quality of both chemical and biological data. Prior to the study the data was rigorously quality controlled and a data base prepared (see 'Materials and methods'). The geographical location of the fields selected are shown in Fig. 2.

The main purpose of this paper is to illustrate contaminant gradients using chemical data alone, to assess how contamination affects benthic fauna both spatially and temporally, and to evaluate commonly used measures of effects such as diversity indices and indicator species compared with multivariate analyses.

\section{MATERIALS AND METHODS}

Surveys are conducted in a similar manner following directives prepared by the Norwegian State Pollution
Control Authority (Anon 1989), with a subsequent more detailed revision (Anon 1990). Surveys done before 1988 may have a slightly different design, but this should not influence the results.

The basic design is a cross which intersects at the centre of the field with sampling stations placed at geometrically increasing distances from the centre (viz. 250,500, 1000, 2000, $4000 \mathrm{~m}$ ). Ore axis is located along the dominant residual current direction and often samples are taken to increased distances along this axis. A reference point should be sited at $10 \mathrm{~km}$ distance, usually located upstream of the predominant current direction. Stations are located using either a Decca navigator system or more recently GPS systems with an accuracy of $\pm 30 \mathrm{~m}$. Fig. 3 shows a typical design (Valhall 1991). Older fields monitored before the sampling manuals were implemented may have a different design (e.g. Ekofisk; Gray et al. 1990).

At each station samples were taken with a Van Veen grab $\left(0.1 \mathrm{~m}^{2}\right)$ with 5 replicates for analyses of benthic macrofauna and 3 replicates for analyses of sediment variables. The biological samples were extracted using $1 \mathrm{~mm}$ mesh sieves and the material fixed in formalin and analysed in the laboratory, For physical and chemical analyses subsamples were taken from the top of the grab, using the upper $5 \mathrm{~cm}$ for physical analyses and upper $1 \mathrm{~cm}$ for chemical analyses. The depth of each sampling station, sediment colour, water content, grain size distribution and sorting, skewness and kurtosis and total organic carbon (TOC) were reported for ail fields. Samples for metal analyses were placed directly in PVC containers and frozen at $-20^{\circ} \mathrm{C}$. The following heavy metals were routinely determined: $\mathrm{Fe}_{1} \mathrm{Cu}, \mathrm{Zn}, \mathrm{Pb}, \mathrm{Ba}, \mathrm{Sr}, \mathrm{Cd}, \mathrm{Cr}$ and $\mathrm{Hg}$. Dried samples were digested with $7 \mathrm{~N} \mathrm{HNO}_{3}$ (Norwegian Standard, NS 4770). Samples for hydrocarbons were wrapped in aluminium foil and frozen at $-20^{\circ} \mathrm{C}$ for subsequent analyses of total hydrocarbon content (THC), aromatic hydrocarbons (NPD and $\mathrm{C}_{1}$ to $\mathrm{C}_{3}$ homologues), bicyclanes ( $\mathrm{C}_{5}$ to $\mathrm{C}_{8}$ decalines) and the pristane/phytane ratio (see the manual of recommended monitoring methods; Anon 1990).

Since the present paper is primarily biological the details of the methods used for chemical analyses are 


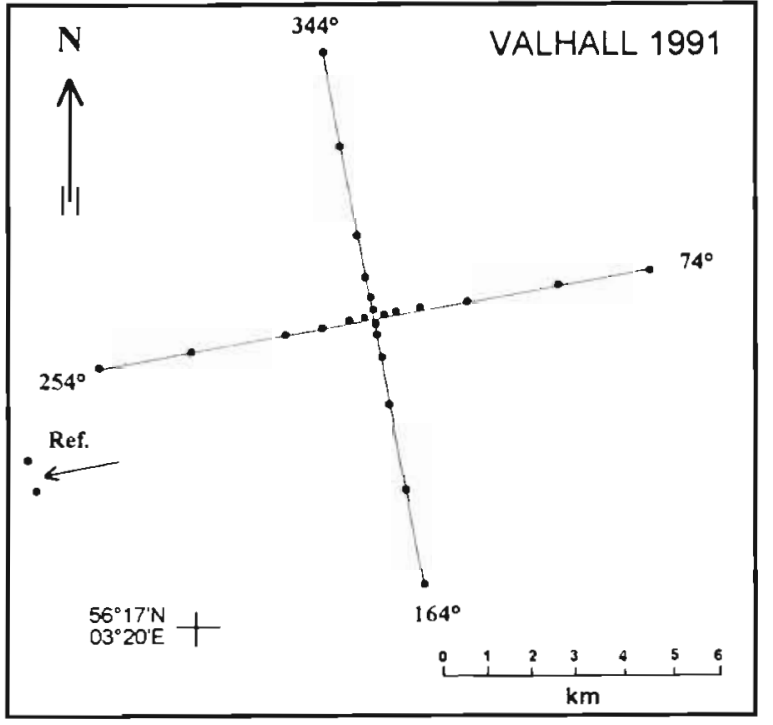

Fig. 3. A typical sampling design (Valhall 1991) with stations in a cross centred at the platform and reference station(s) 10 to $15 \mathrm{~km}$ distant against the predominant current direction

not described, but can be found in Anon (1989, 1990). Quality assurance procedures were mandatory for all chemical analyses.

Species identification was undertaken by a series of consultants and institutions. A database containing chemical and biological data was established. Only species that had been approved by the Riksmuseum Stockholm were added to the faunal list, thus synonyms and obvious misidentifications were excluded [see Stovring (1994) for a complete list of the species found]. Minor taxonomic groups, however, receive variable attention and faunal groups not properly sampled by the methods used, such as meiofaunal nematodes, Foraminifera, inhabitants of hard substrata such as Porifera, Bryozoa and Cirripedia, were not included. Similarly juveniles were excluded and unidentified species were included only if another species had been identified within the same genus.

Statistical treatment. Environmental variables: Variables analysed were depth, median grain size $(\mathrm{Md} \varphi)$, sediment sorting (inclusive standard deviation, SD), sediment skewness and kurtosis, sediment \% siltclay $(<63 \mu \mathrm{m})$, TOC, and concentrations of barium $(\mathrm{Ba})$, strontium $(\mathrm{Sr})$, lead $(\mathrm{Pb})$, iron $(\mathrm{Fe})$, copper $(\mathrm{Cu})$, cadmium (Cd), chromium ( $\mathrm{Cr})$, zinc $(\mathrm{Zn})$ and THC. Plots of the environmental variables using the quantile method in SYSTAT 5.0 (Systat, Inc., Evanston, IL, USA) clearly indicated that a $\log _{10}$ transformation was best prior to multivariate analyses and therefore a $\log _{10}$ transformation was used. Due to different scales each environmental variable was also normalised (by subtracting mean across stations and dividing by SD). The data were subjected to hierarchical, agglomerative classification employing group-average linking (Lance \& Williams 1967) with Euclidean distance as the distance measure. Classification analyses were performed using the CLUSTER program in the PRIMER (Plymouth Routines In Multivariate Ecological Research) package.

Non-normalised environmental variables were further subjected to Principal Component Analysis (PCA) performed on a correlation matrix (a 'species'-centred and standardised PCA) using the CANOCO package (ter Braak 1988, 1990). In a standardised PCA, a normalisation of the data, as above, is implicit. The resulting groups from the classification analysis were superimposed on the PCA plots. Correlation plots of environmental variables were also constructed in order to illustrate the strength of correlations of variables with the putative gradient of the PCA axes. PCA ordination and correlation plots were constructed with the drawing program CANODRAW (Smilauer 1992).

Faunal analyses: In order to obtain the most ecologically meaningful results the species data matrices, containing pooled data from the replicates from each station, were analysed with either no transformation or using single or double square root transformation depending on the numerical dominance in each separate matrix. The CLUSTER program in PRIMER was used to compute similarity matrices based on the BrayCurtis similarity coefficient (Bray \& Curtis 1957) and the similarity matrices were then subjected to hierarchical, agglomerative classification employing groupaverage sorting (Lance \& Williams 1967) to classify the stations based on faunal groupings. Non-metric Multidimensional Scaling analyses (MDS ordination; Shepard 1962, Kruskal 1964a, b) were done using PRIMER on the similarity matrices obtained using the BrayCurtis coefficient. Goodness-of-fit in the MDS ordination plots was measured as stress with Kruskal's stress formula I (Kruskal \& Wish 1978). Detrended Correspondence Analysis (DCA ordination; Hill 1979, Hill \& Gauch 1980) was done using the CANOCO package. The implied distance measure is chi-square distance on the original data matrices. Classification and 2 different ordination methods were used to ensure that the underlying community structure is well defined. The choice of ordination technique that best summarises the 'true' pattern in the field data is most desirable. However, one cannot know a priori which method is likely to reveal the optimal result (Minchin 1987), and the results from a number of analyses methods must therefore be compared (Jackson 1993). If similar patterns are found using several methods, then the result should be representative (Green 1979). For the ordinations we have made comparisons between MDS and DCA plots, but the results were seldom different indi- 
cating congruent solutions and thus only one of the results, usually the MDS plot, is illustrated as an example.

Following the division into station groups from the classification and ordination results, the species having the greatest contribution to this division were determined using the similarity percentages program SIMPER (Clarke 1993), available in the PRIMER package.

Linking of environmental variables and fauna: In order to demonstrate the most important environmental variables related to faunal patterns 2 entirely different methods were employed: forward selection in a hybrid CA/CCA ordination in the CANOCO package and rank correlations between PCA and MDS ordinations with the program BIOENV (Clarke \& Ainsworth 1993) in the PRIMER package. We believe in applying different techniques in order to check the validity of the extracted explanatory variables. However, here the 2 methods mainly gave consistent results, but some important differences were also apparent.

Firstly, a forward selection of all the environmental variables was performed in a hybrid CA/CCA ordination. This method is named hybrid because it combines an unconstrained ordination (CA) with a constrained canonical ordination (CCA) in a single analysis. The proportion of the total faunal variance (= sum of all eigenvalues, called total inertia in CANOCO) which can be accounted for by the environmental variables can be estimated as the ratio of eigenvalues of constrained versus unconstrained axes. From this ratio, the percentage value which indicates the percentage explanation of each separate environmental variable to the total faunal variance was calculated. Constrained axes are constructed to maximise the fit with linear combinations of environmental variables, and remaining, unconstrained axes represent a residual variation in data after extracting the constrained axes. Whether the environmental variables were significantly correlated to the faunal ordinations was tested with unrestricted Monte Carlo permutation tests (99 permutations) for all the environmental variables in each dataset (ter Braak 1990).

BIOENV was the second method used for extracting important explanatory variables. This harmonic analysis uses a weighted Spearman's rank correlation between the resulting ranked similarity matrices which underlie the MDS ordinations of fauna and correlation-based PCA ordinations of the environmental variables. Use of a correlation-based PCA implies that a normalisation of environmental data is not necessary prior to this analysis. From each survey the 8 most important environmental variables, obtained from forward selection in the CA/CCA analyses, were used as input variables in the BIOENV program. The variable or combinations of variables which give the highest correlation coefficient is assumed to be the most important explanatory variable(s). In addition for some of the fields (baseline surveys) the relationships between community structure and environmental variables were illustrated by correlating the obtained axes in DCA ordinations with the environmental variables resulting in a biplot, using the CANOCO package and the CANODRAW program.

\section{RESULTS}

Biological data and environmental variables from 14 fields comprising 24 different surveys have been analysed. A summary of basic biological and environmental data is shown in Table 2. The study contains data collected between 1985 and 1993 at depths between 63 and $380 \mathrm{~m}$.

\section{Baseline studies}

Four examples of results from baseline studies (Heidrun 1988, Snorre 1989, Togi 1989, Mime 1990) are shown. Fig. 4 shows the biplots of the DCA faunal ordinations of stations and the measured environmental variables. In this analysis the DCA ordinations are run separately followed by a correlation between the environmental variables and the obtained axes. The environmental variables are illustrated by arrows for each variable, whose direction indicates maximum correlation with stations along the same axis. The faunal ordinations showed typical 'shotgun' plots with a concentration of stations and no clear patterns at Heidrun and Togi. By contrast, at Snorre there was a clear correlation between depth (and co-related variables) and the fauna; the stations were divided into 2 groups, deeper (right) and shallower (left) than $320 \mathrm{~m}$. At the Mime field the most important environmental variable was the TOC of the sediment.

Results of the MDS ordinations, together with plots of the classification analyses (dendrograms) and plots of the classification groupings on the original sampling stations for the fauna, are shown in Fig. 5. No clear patterns were found, except for the effect of the depth change across the Snorre field where the fauna was separated into 2 main depth groups, $<320 \mathrm{~m}$, group a and $>320 \mathrm{~m}$, groups b to g (compare with Fig. 4). Another indication of the lack of clear faunal gradients in these baseline surveys is also shown by the relatively high stress values obtained in the MDS ordinations, except for Mime which had few stations and as a consequence a low stress value is expected.

Table 3 shows data for the relations between environmental data and the fauna and shows that there was no 
Table 2. Summary showing fields and some basic data, with ranges where applicable. Total S: total number of species found at the field; S: number of species per station; N: number of individuals per station; $H^{\prime}$ : Shannon-Wiener diversity index; Ba: barium; THC: total hydrocarbons; $\mathrm{Zn}$ : zinc; Pb: lead. Concentrations as $\mathrm{mg} \mathrm{kg}^{-1}$ dry weight. -: not measured

\begin{tabular}{|c|c|c|c|c|c|c|c|c|c|c|c|}
\hline Field & Year & $\begin{array}{l}\text { No. of } \\
\text { stations }\end{array}$ & $\begin{array}{c}\text { Depth } \\
\text { (m) }\end{array}$ & Total S & $\begin{array}{c}S \\
\left(0.5 \mathrm{~m}^{2}\right)\end{array}$ & $\begin{array}{c}\mathrm{N} \\
\left(0.5 \mathrm{~m}^{2}\right)\end{array}$ & $\begin{array}{c}H^{\prime} \\
\left(0.5 \mathrm{~m}^{2}\right)\end{array}$ & $\frac{\mathrm{Ba}}{\left(\mathrm{mg} \mathrm{kg}^{-1}\right)}$ & $\begin{array}{c}\mathrm{THC} \\
\left(\mathrm{mg} \mathrm{kg}^{-1}\right)\end{array}$ & $\frac{\mathrm{Zn}}{\left(\mathrm{mg} \mathrm{kg}^{-1}\right)}$ & $\begin{array}{c}\mathrm{Pb} \\
\left(\mathrm{mg} \mathrm{kg}^{-1}\right)\end{array}$ \\
\hline Heidrun & 1988 & 25 & $320-380$ & 192 & $46-81$ & $141-448$ & $3.69-5.46$ & $65-543$ & $1.4-5.5$ & $32-56$ & $11-26$ \\
\hline Snorre & 1989 & 20 & $288-340$ & 319 & $59-114$ & $162-525$ & $4.73-5.81$ & $94-2007$ & $1.0-6.2$ & $17-30$ & $4.6-16.6$ \\
\hline Togi & 1989 & 21 & $299-303$ & 111 & $24-43$ & $83-166$ & $3.74-4.39$ & $129-355$ & $4.3-9.2$ & $59-74$ & $30-42$ \\
\hline Mime & 1990 & 11 & 80 & 162 & $51-99$ & $319-528$ & $4.22-5.54$ & $38-197$ & $1.6-5.1$ & $7-13$ & $6.9-10.7$ \\
\hline Oseberg $\mathrm{S}$ & 1989 & 23 & $105-115$ & 207 & $26-62$ & $151-1240$ & $2.21-5.30$ & $34-5520$ & $1.2-7770.7$ & $4-52$ & $2.3-58.3$ \\
\hline Gullfaks A & 1989 & 16 & $131-140$ & 248 & $42-109$ & $264-1054$ & $3.74-5.36$ & $99-5000$ & $1.3-519.3$ & $10-62$ & $5.3-15$ \\
\hline Hod & 1991 & 24 & $63-70$ & 144 & $32-56$ & $169-650$ & $3.20-4.60$ & $15-2393$ & $3.2-1201$ & $4-19$ & $4.6-23$ \\
\hline Valhall & 1985 & 13 & $65-68$ & 73 & $4-34$ & $74-502$ & $0.57-3.94$ & $280-96000$ & $5.4-72000$ & $12-180$ & $80-375$ \\
\hline Valhall & 1988 & 20 & $65-69$ & 96 & $21-47$ & $201-1868$ & $0.71-4.47$ & $97-8433$ & $9.9-5493.3$ & $9.4-31$ & $5.3-15.8$ \\
\hline Valhall & 1991 & 16 & $65-69$ & 156 & $9-66$ & $261-3583$ & $0.04-4.77$ & $55-6670$ & $4.3-13065$ & $6.6-55.6$ & $6.5-55.6$ \\
\hline Gyda & 1987 & 18 & 65 & 106 & $26-43$ & $102-209$ & $3.94-4.68$ & $241-591$ & $2.5-4.0$ & $8-13$ & $9-14$ \\
\hline Gyda & 1990 & 17 & 65 & 139 & $14-70$ & $136-1600$ & $0.49-4.98$ & $270-3297$ & $2.1-1133.3$ & $10.3-33.3$ & $9.7-27.7$ \\
\hline Gyda & 1993 & 20 & 65 & 156 & $29-67$ & $255-2270$ & $1.00-4.83$ & $55-3078$ & $0.3-49.2$ & $5.9-17.3$ & $4-6.8$ \\
\hline Veslefrikk & 1987 & 10 & $171-181$ & 127 & $43-62$ & $115-240$ & $4.38-5.17$ & $90-355$ & $7.2-15.7$ & $8.6-31$ & $1-11$ \\
\hline Veslefrikk & 1990 & 16 & $171-186$ & 238 & $71-104$ & $231-3290$ & $3.40-5.79$ & $214-6033$ & $3.7-5596.7$ & $6.2-29.4$ & - \\
\hline Veslefrikk & 1993 & 14 & $171-186$ & 267 & $61-122$ & $507-11600$ & $2.09-5.62$ & $357-6350$ & $5.8-153$ & $7.6-148$ & $5.3-153$ \\
\hline Gullfaks B & 1990 & 12 & $134-193$ & 160 & $22-67$ & $49-548$ & $2.65-5.38$ & $37-6967$ & $0.5-4077$ & $8.3-42.0$ & $6.4-34.8$ \\
\hline Gullfaks B & 1993 & 13 & $133-196$ & 248 & $58-116$ & $441-2680$ & $2.08-5.15$ & $49-5340$ & $1.2-234$ & $7.3-116$ & $4.4-62.2$ \\
\hline Statfjord A & 1990 & 10 & $141-149$ & 198 & $29-82$ & $491-1780$ & $2.47-5.32$ & $460-7203$ & $6.4-6696.7$ & $15.9-1430$ & $5.5-133$ \\
\hline Statfjord A & 1993 & 11 & $140-144$ & 225 & $50-101$ & $464-9410$ & $2.09-5.60$ & $1040-73302$ & $21.1-736$ & $16.5-701$ & $7.9-311$ \\
\hline Statfjord B & 1990 & 9 & $140-145$ & 199 & $57-98$ & $448-1200$ & $3.46-5.25$ & $513-7870$ & $6.4-2516.7$ & $12.4-331$ & $4.7-57.6$ \\
\hline Statfjord B & 1993 & 11 & $140-145$ & 235 & $62-113$ & $457-3210$ & $1.93-5.67$ & $376-6020$ & $9.5-165$ & $14.5-259$ & $7.9-200$ \\
\hline Statfjord C & 1990 & 10 & $136-143$ & 165 & $9-84$ & $248-1350$ & $1.30-5.15$ & $234-7330$ & $6.1-38333$ & $10.0-399.7$ & $75.1-173.7$ \\
\hline Statfjord C & 1993 & 13 & $136-143$ & 249 & $39-114$ & $167-8570$ & $1.92-5.48$ & $201-6630$ & $7.3-5860$ & $11.9-341$ & $5.8-156$ \\
\hline
\end{tabular}

consistent pattern of variables that influenced the fauna and that the most important (highest ranked) variables varied from one field to another. Weightings (Table 3a) were low (with 1 exception $\leq 12.1 \%$ ), and the correlation coefficients (Table $3 \mathrm{~b}$ ) were also, with few exceptions, low. Although the correlations between faunal compo-

Table 3. Relationship between environmental variables and fauna using forward selection in CANOCO (a) and BIOENV in PRIMER (b) for baseline surveys. The 5 environmental variables best explaining the faunal patterns are given. In forward selection, the percentage explanation of each environmental variable to the total faunal variance is given together with the level of significance $\left(" p<<0.01_{i} \cdot p<0.05 i^{n s}\right.$ not significant). The correlation coefficient $\left(r_{s}\right)$ for a weighted Spearman rank correlation is given in (b)

\begin{tabular}{|c|c|c|c|c|c|c|c|}
\hline \multicolumn{2}{|c|}{ Heidrun 1988} & \multicolumn{2}{|c|}{ Snorre 1989} & \multicolumn{2}{|c|}{ Togi 1989} & \multicolumn{2}{|c|}{ Mime 1990} \\
\hline \multicolumn{8}{|c|}{ (a) Forward selection } \\
\hline $\mathrm{Cd}$ & $7.1 \%$ & Depth & $10.4 \%$ & Md $\varphi$ & $7.0 \%{ }^{\mathrm{ns}}$ & TOC & $24.1 \%$ \\
\hline Depth & $6.4 \%$ ns & $\mathrm{Zn}$ & $8.1 \% \cdots$ & $\mathrm{Fe}$ & $6.1 \%$ ns & Sorting & $12.1 \%{ }^{\mathrm{ns}}$ \\
\hline$<63 \mu \mathrm{m}$ & $6.4 \%$ ns & TOC & $7.0 \%$ & $\mathrm{Zn}$ & $6.1 \%$ ns & $\mathrm{Pb}$ & $12.1 \%$ ns \\
\hline Sorting & $5.7 \%$ ns & $\mathrm{Pb}$ & $7.0 \% \cdots$ & $<63 \mu \mathrm{m}$ & $5.0 \%$ ns & Skewness & $12.1 \% \mathrm{n}^{\mathrm{n}}$ \\
\hline $\mathrm{Cr}$ & $5.0 \%{ }^{n s}$ & Sorting & $6.4 \% \cdots$ & $\mathrm{Ba}$ & $5.0 \%^{\mathrm{ns}}$ & $\mathrm{Cd}$ & $12.1 \%^{\mathrm{ns}}$ \\
\hline \multicolumn{8}{|l|}{ (b) BIOENV } \\
\hline $\mathrm{Cd}$ & $r=0.256$ & Depth & $r=0.448$ & $\mathrm{Ba}$ & $\mathrm{r}=-0.041$ & TOC & $r=0.353$ \\
\hline Depth & $\mathrm{r}=0.219$ & $\mathrm{Zn}$ & $r=0.302$ & $\mathrm{Fe}$ & $x=-0.044$ & $<63 \mu \mathrm{m}$ & $r=0.075$ \\
\hline $\mathrm{Zn}$ & $I=0.207$ & $\mathrm{Cu}$ & $r=0.194$ & $<63 \mu \mathrm{m}$ & $\mathrm{r}=-0.067$ & $M d \varphi$ & $r=0.046$ \\
\hline $\mathrm{Md} \varphi$ & $I=0.203$ & $<63 \mu \mathrm{m}$ & $\mathrm{r}=0.177$ & $\operatorname{Md} \varphi$ & $r=-0.069$ & $\mathrm{Cd}$ & $r=-0.058$ \\
\hline$<63 \mu \mathrm{m}$ & $I=0.123$ & Sorting & $r=0.163$ & $\mathrm{~Pb}$ & $r=-0.076$ & Skewness & $r=-0.064$ \\
\hline \multicolumn{2}{|c|}{ Max. corr.: } & \multicolumn{2}{|c|}{ Max corr.: } & \multicolumn{2}{|c|}{ Max. corr. } & \multicolumn{2}{|l|}{ Max. corr: } \\
\hline \multirow{2}{*}{\multicolumn{2}{|c|}{$\begin{array}{l}\text { Cd, Depth, Zn, }<63 \mu \mathrm{m} \text {, } \\
\text { Sorting, Skewness }\end{array}$}} & \multicolumn{2}{|c|}{ Depth, Zn } & \multicolumn{2}{|c|}{$\begin{array}{l}\mathrm{Ba}, \mathrm{Fe},<63 \mu \mathrm{m} \\
\mathrm{r}_{\mathrm{s}}=0.025\end{array}$} & \multicolumn{2}{|l|}{$\begin{array}{l}\text { TOC } \\
I_{s}=0.353\end{array}$} \\
\hline & & $\mathrm{r}_{\mathrm{s}}=0.462$ & & $r_{s}=0.02 s$ & & $I_{\mathrm{s}}=0.353$ & \\
\hline
\end{tabular}




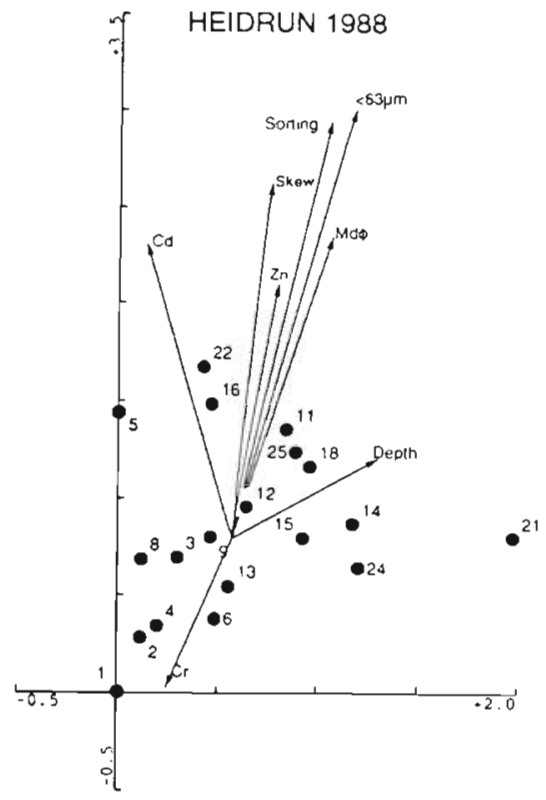

SNORRE 1989
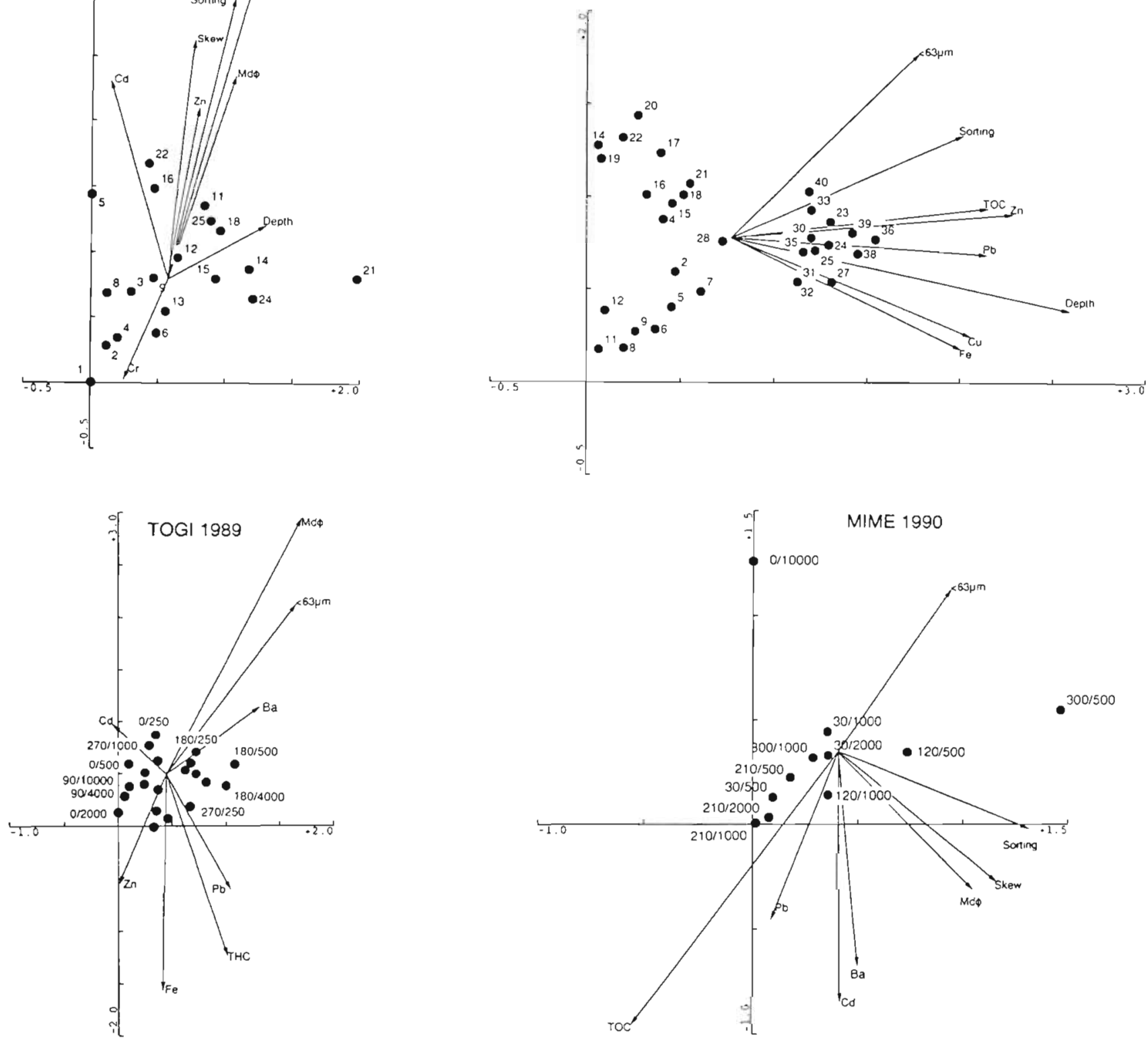

Fig. 4. Biplot of DCA faunal ordinations and the 8 most important environmental variables within each field (based on forward selection in CANOCO). For Heidrun and Snorre fields the stations are given as numbers, while for Togi and Mime fields the stations are given as bearing and direction from the platform (e.g. $180 / 500$ is the station along the $180^{\circ}$ bearing $500 \mathrm{~m}$ away from the platform). Not all stations are plotted to avoid overcrowded figures. All stations are given in the corresponding MDS plots in Fig. 5

sition and the environmental variables were in most cases weak, there was a high degree of consistency in the 2 methods applied, in both weight and rank within fields. At the Snorre field depth and related variables played an important role, despite the fact that the variation in depth was relatively small (288 to $340 \mathrm{~m}$ ). At the Mime field the TOC content was the principal environmental variable, whereas the other variables showed a more random rank order in the 2 methods due to similarly low values.

\section{Development of contamination}

Contamination is usually regarded as a significant increase in concentration of a chemical over a back- 

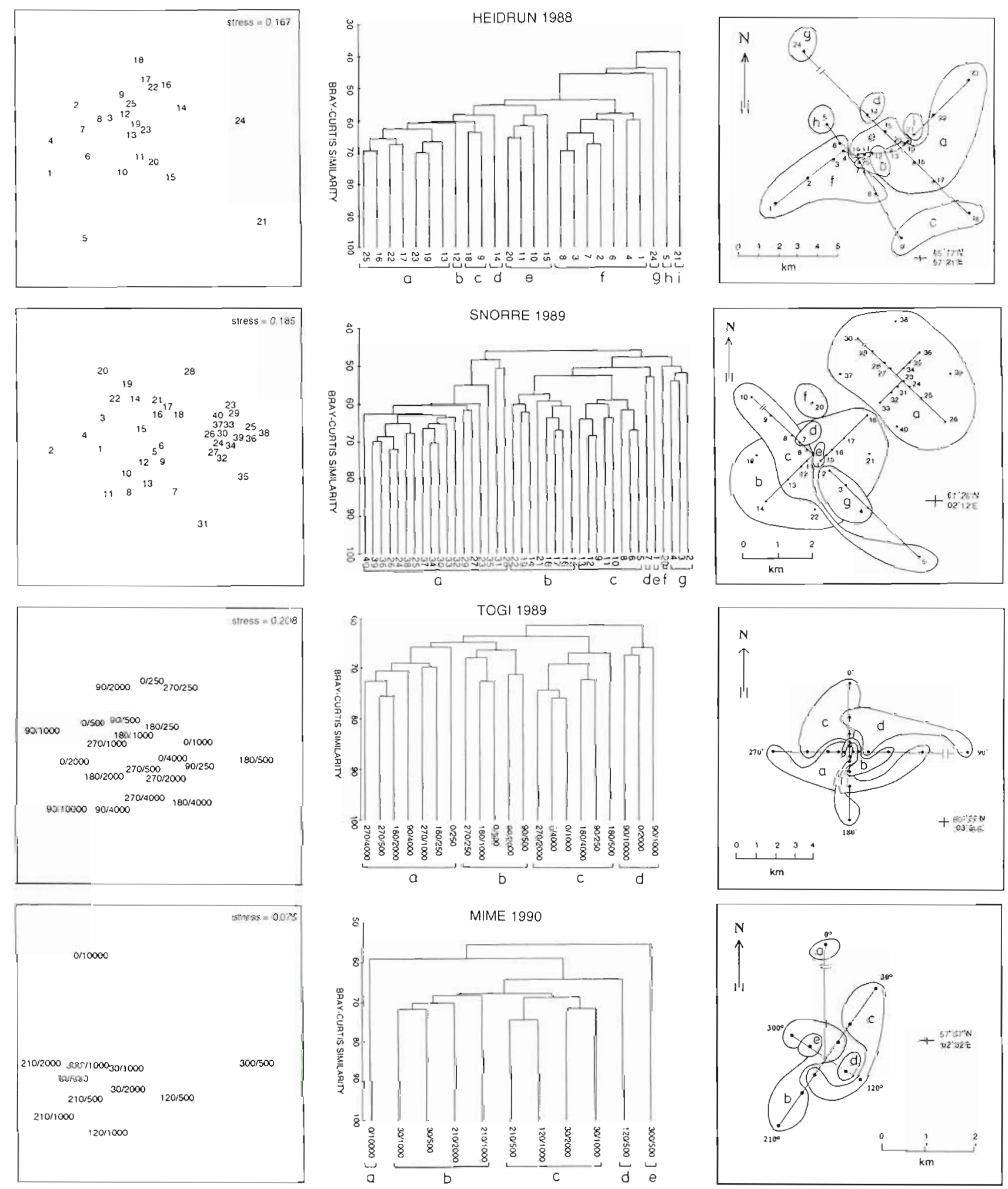

Fig. 5. MDS ordination plots of the stations at the Heidrun, Snorre, Togi and Mime fields according to faunal composition; MDS ordination (left), classification (centre) and plots of the classification groupings on the original sampling stations (right) 


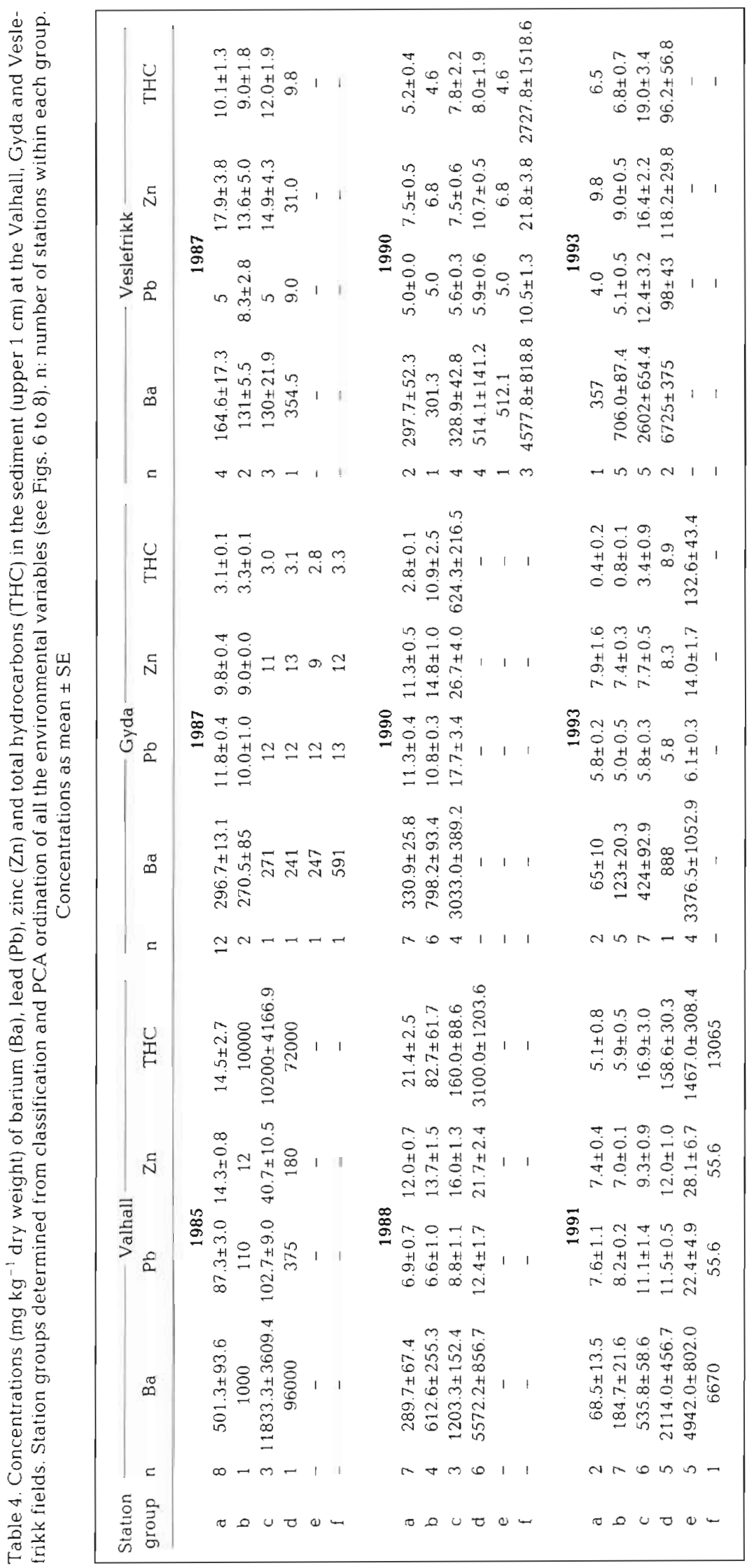

ground level. This increase may or may not lead to effects on biological systems. In this study we have used multivariate, rather than the more commonly used univariate analyses, to analyse patterns of contamination. Also depth and environmental variables that characterise the sediment composition (Md $\varphi$, sorting, skewness, kurtosis, \% silt-clay and TOC) are included in these analyses because patterns may be related both to changes in these variables and to chemical variables. Here contamination is assessed by classification analyses and PCA ordinations of the measured environmental variables which include drilling-related variables such as $\mathrm{Ba}, \mathrm{Sr}$, THC and heavy metals. It is expected that if contamination is not in evidence there will be no obvious pattern and a more or less random distribution of stations will be obtained, as in the results from the baseline surveys (Figs. $4 \& 5$ ). If contamination is present then gradients radiating from the centre of the field should occur. To illustrate this approach 3 fields have been selected where there have been clear increases in contamination over time. The fields are Valhall (1985, 1988 and 1991), Gyda (1987, 1990 and 1993) and Veslefrikk (1987, 1990 and 1993).

Figs. 6, 7 \& 8 show for Valhall, Gyda and Veslefrikk, respectively, the station groups obtained from the classification analyses of the environmental variables, superimposition of these groups on the PCA plots and superimposition of the resulting groups on the sampling locations. In order to give an indication of the levels of some of the measured environmental variables, Table 4 shows the concentrations of $\mathrm{Ba}, \mathrm{Pb}, \mathrm{Zn}$ and $\mathrm{THC}$ in the sediment within each station group.

For the Valhall field, Fig. 6 shows that in 1985 the innermost stations $250 \mathrm{~m}$ away from the platform were grouped together, groups $c$ and $d$, which were severely contaminated (high levels compared to background; see Table 4) especially with $\mathrm{Ba}_{2} \mathrm{Sr}$ and hydrocarbons. Contamination was also found out to $2000 \mathrm{~m}$ along the $74^{\circ}$ axis, group $\mathrm{b}$, yet most stations, group $a$, were not 

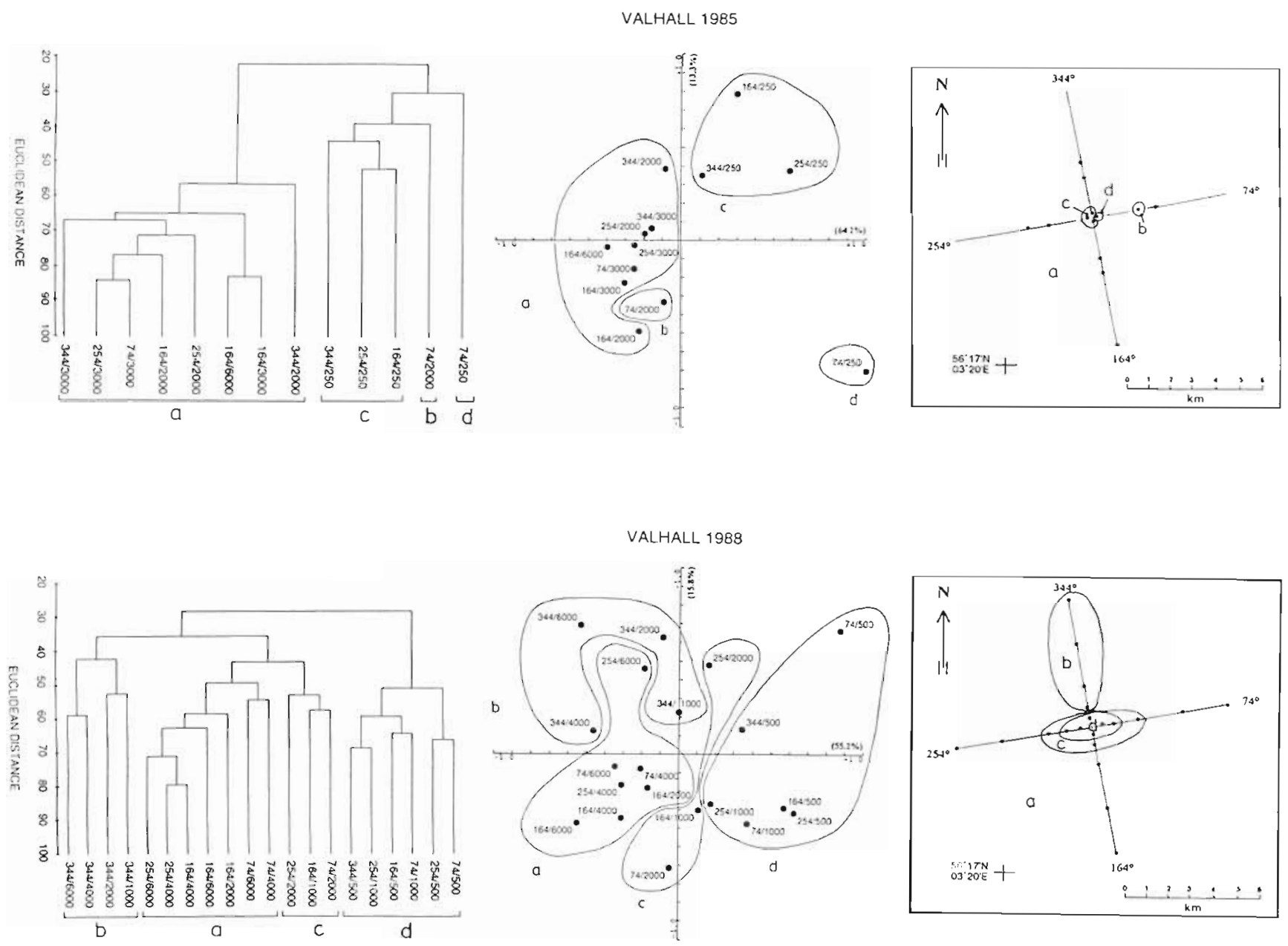

VALHALL 1991
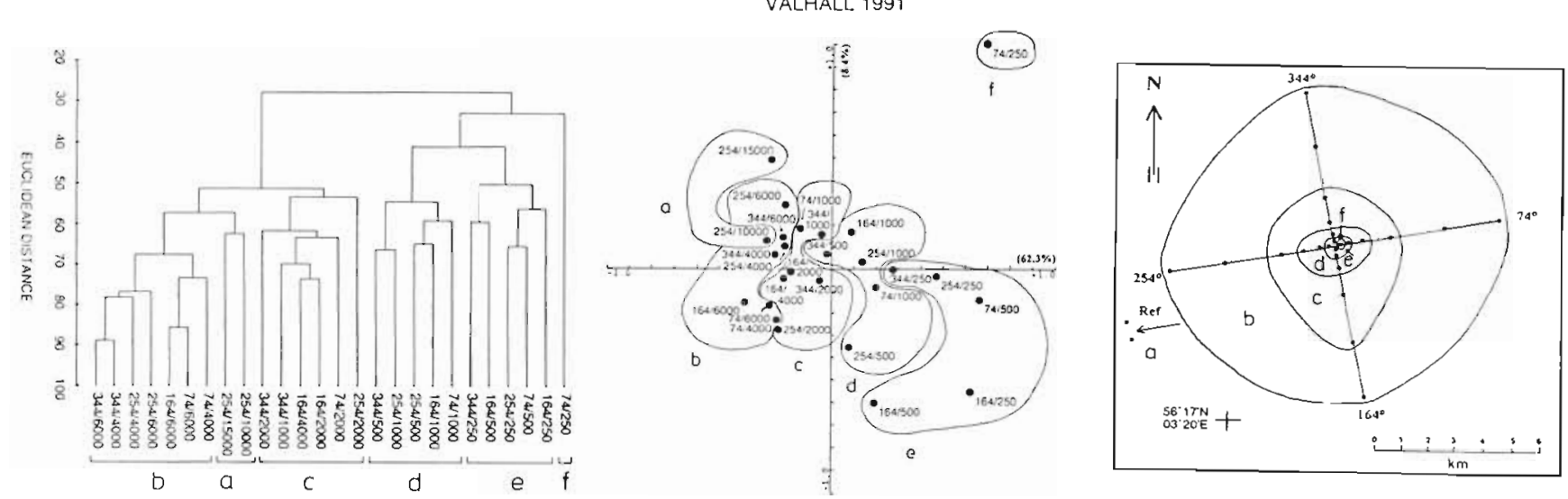

Fig. 6. Classification of stations according to environmental variables (left), superimposition of these groups on the PCA plots (centre) and the groupings on the original sampling stations at the Valhall field. In 1985 the explained variance in the PCA plot along Axis 1 was $64.2 \%$ and for Axis 2, 13.3\%. The corresponding values for 1988 were $55.2 \%$ and $15.8 \%$, and in 1991 these were $62.3 \%$ and $8.4 \%$ 
GYDA 1987
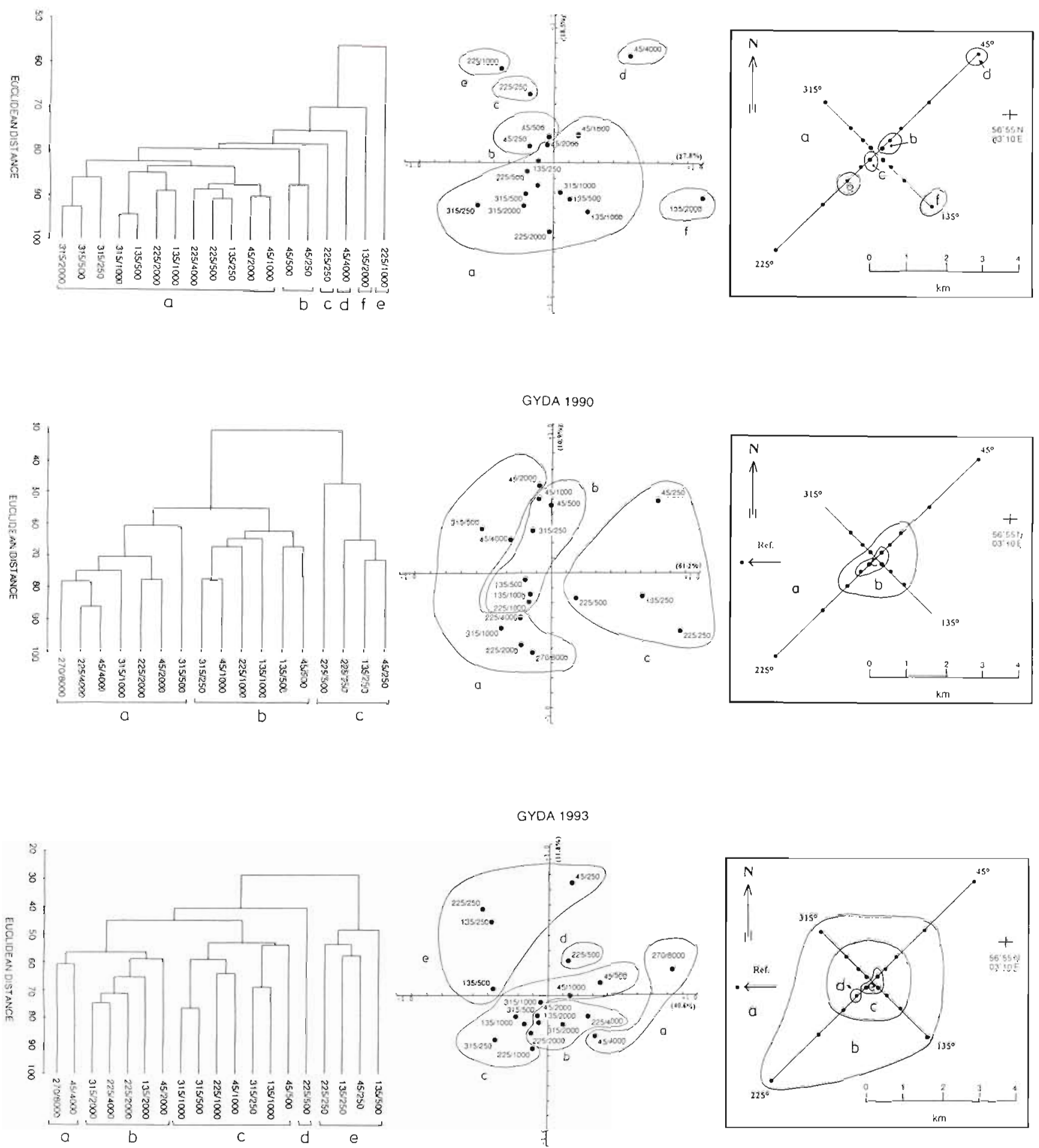

Fig. 7. As for Fig. 6, but for the Gyda field. 1987: Axis 1, 27.8\%; Axis 2, 18.5\%. 1990: Axis 1, 61.2\%; Axis 2, 10.9\%. 1993: Axis 1, $40.8 \%$; Axis 2. $11.8 \%$ 

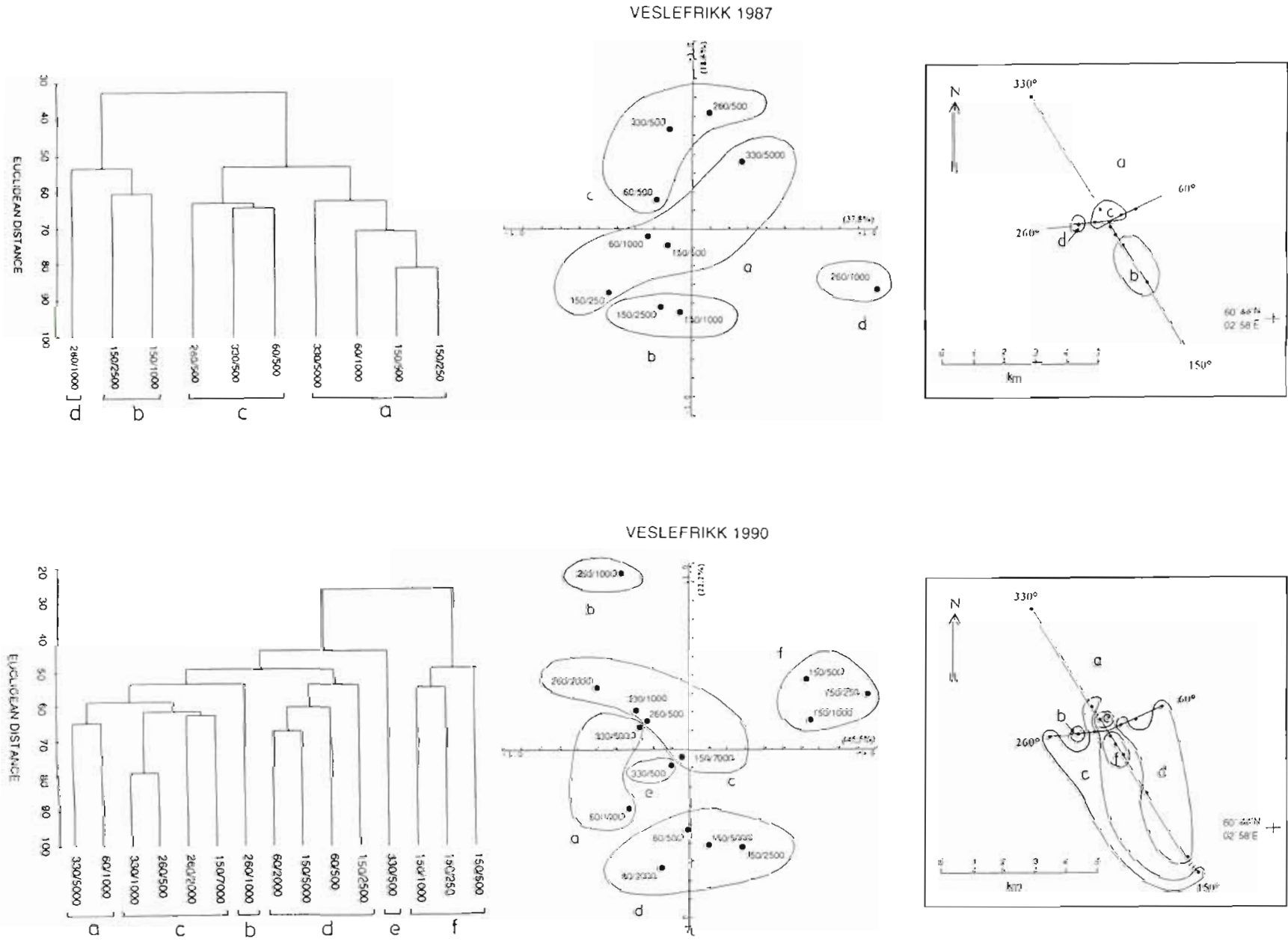

VESLEFRIKK 1993
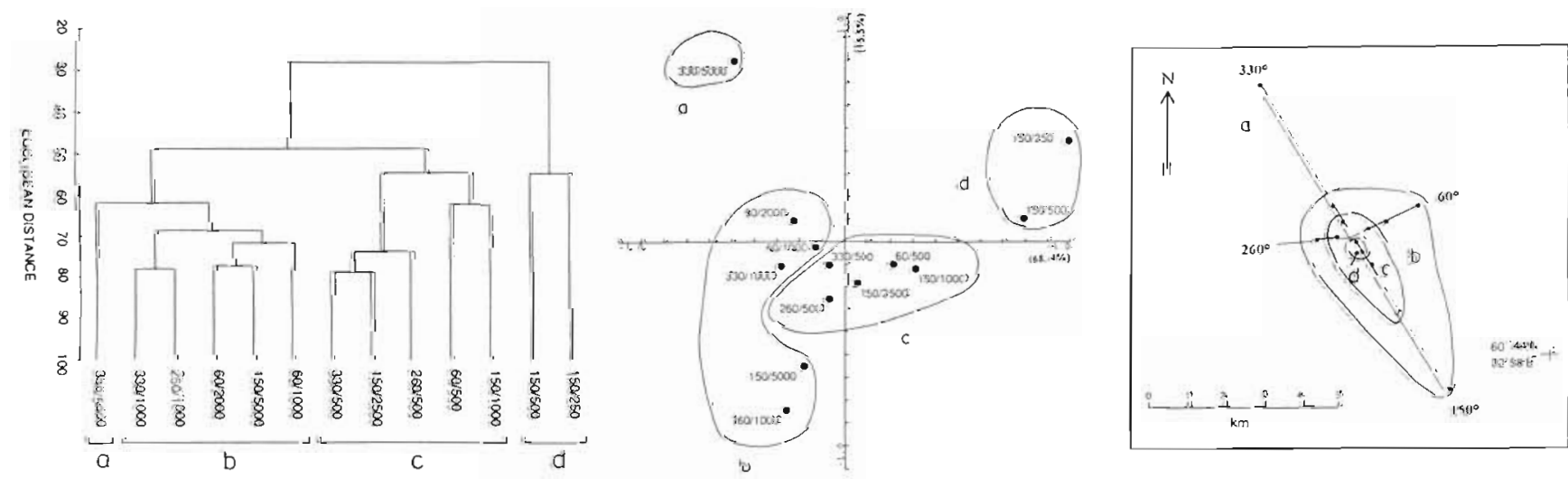

Fig. 8. As for Fig. 6, but for the Veslefrikk field. 1987: Axis 1, 37.8\%; Axis 2, 18.6\%. 1990; Axis 1, 45.5\%; Axis 2. 22.2\%. 1993: Axis $1,68.4 \%$; Axis $2,15.5 \%$ 
contaminated. By 1988 the area contaminated had increased and included station groups b, c and d (Fig. 6. Table 4). By 1991 all stations differed from the reference stations suggesting that the whole field was contaminated out to $6000 \mathrm{~m}$ on all axes.

It is of interest to find which environmental variable(s) were responsible for the observed grouping of stations, especially that leading to contamination at the outermost group b compared with the reference group a (Fig. 6). Barium is a good tracer for dispersal of drill-cuttings. In order to illustrate relations between concentrations of $\mathrm{Ba}$ in the sediment and the obtained
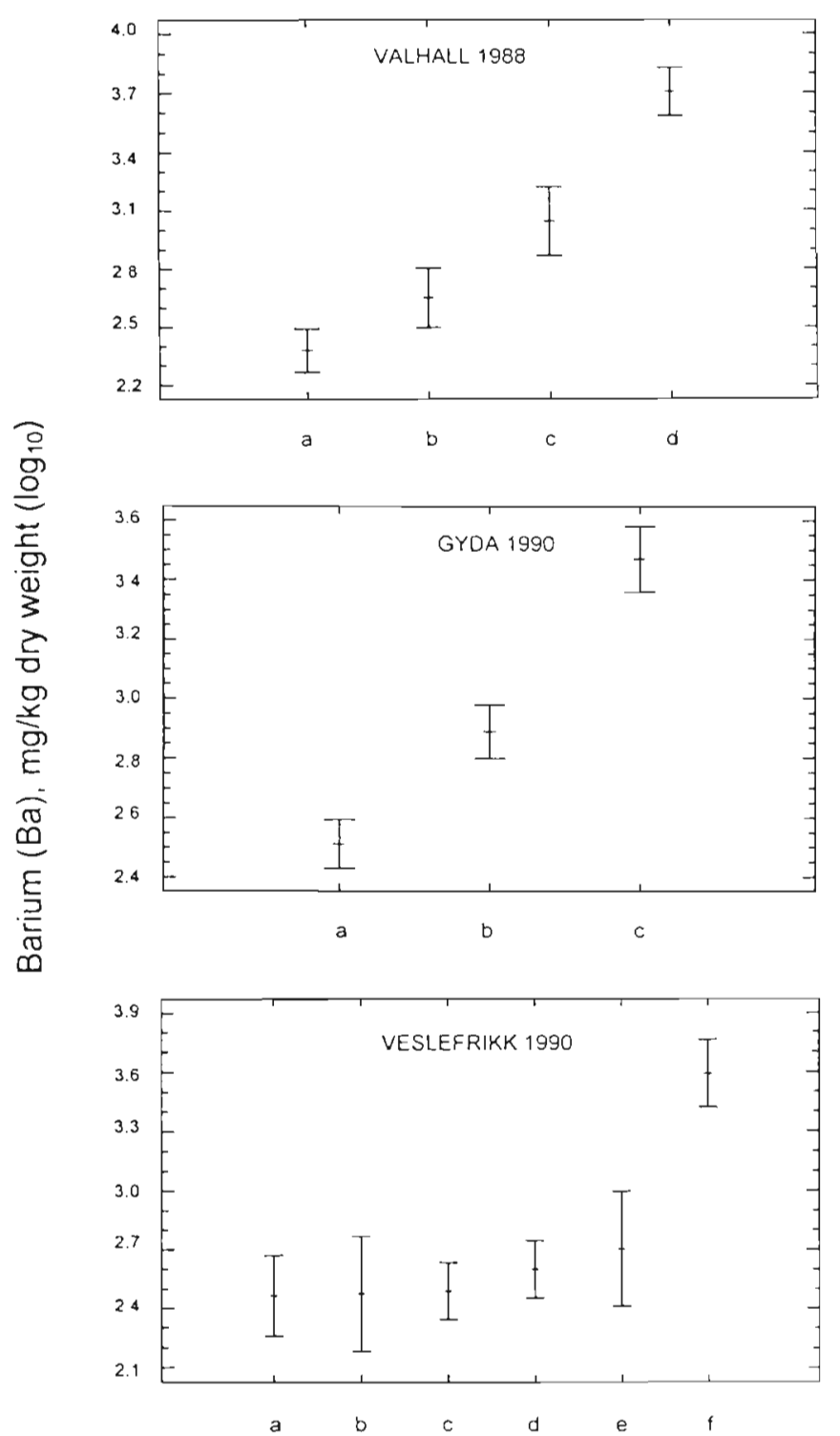

station groups (Figs. 6 to 8), values from the individual stations, each containing 3 replicates, were plotted as means with $95 \%$ confidence intervals (Fig. 9). The plots clearly show, save for Veslefrikk in 1990, a significant increase in the concentrations of $\mathrm{Ba}$ towards the platforms and that the outermost, uncontaminated group a have significantly lower concentrations of Ba in the sediment.

Yet it is not $\mathrm{Ba}$ alone that changes along the gradient. Inspection of the environmental variable data-matrix, and a superimposition of the environmental variables (not shown) on the PCA plot, showed that the variables
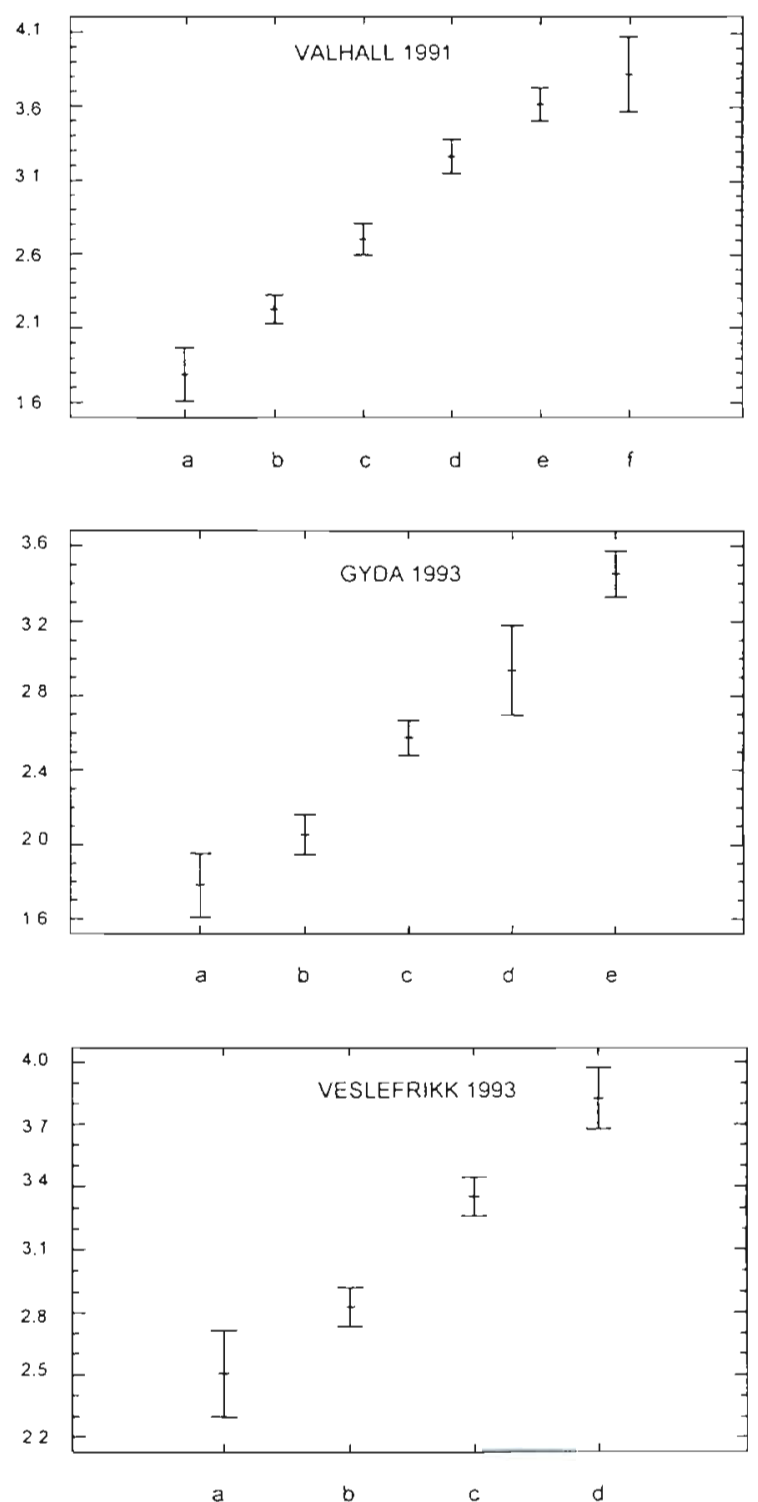

Station groups from classification and PCA ordination

Fig. 9. Sediment concentrations of barium (Ba) within the station groups from classification and PCA ordination at the Valhall, Gyda and Veslefrikk fields. Values given as mean with $95 \%$ confidence intervals 
that divided most clearly between station group a and $\mathrm{b}$ at the Valhall field in 1991 were $\mathrm{Ba}$, Sr and Cu which all showed elevated levels within group b compared to group a. This clearly indicates that discharge from the platform was responsible for the resulting station groupings. The gradient was strong with rings of contaminant radiating from the central point. In spite of an increase in number of sampling stations from 1985 to 1988 , by 1991 the sampling design was no longer appropriate as there were too few control (uncontaminated) stations against which contamination could be assessed. Only the reference stations 10 and $15 \mathrm{~km}$ away were different from those surrounding the platform.

At the Gyda field in 1987 there was no clear pattern of station groupings (Fig. 7). This lack of pattern is typical for most baseline surveys (see above). By 1990 contamination had begun and a gradient of environmental variables emerged, shown as rings around the platform. There was an increase of contamination with increased concentrations in variables related to drillcuttings discharges, e.g. Ba and THC (Table 4). Groups b and $c$, the 2 innermost station groups, had significantly higher barium concentrations compared to the outermost group a (Fig. 9). In 1993, inspection of the environmental data-matrix and superimposition of these on the PCA plot, as above, showed elevated levels of $\mathrm{Ba}, \mathrm{Cd}$ and $\mathrm{THC}$ within station group b compared to station group a, again related to drill-cuttings discharged. By 1993 contamination was clearly evident to $2000 \mathrm{~m}$ along the $45^{\circ}, 135^{\circ}$ and $315^{\circ}$ axes and to $4000 \mathrm{~m}$ along the $225^{\circ}$ axis. Only station $45^{\circ} / 4000 \mathrm{~m}$ and the reference station did not show evidence of contamination. Plot of means and $95 \%$ confidence limits of Ba (Fig. 9) clearly demonstrated a significant relation between discharges of drill-cuttings and Ba levels within the station groups. In 1993, station $45^{\circ} / 4000 \mathrm{~m}$ and the reference station were different from the remaining stations within the field suggesting that, as at Valhall, the sampling design is now unsuitable for monitoring of contamination, which has spread to the outermost stations.

At Veslefrikk in 1987 (Fig. 8) there was no pattern in the station groupings, although 1 group of stations near the platform was apparent (group c). A closer inspection of environmental data (Table 4) showed no elevated levels in station group $\mathrm{c}$ within variables related to discharge of drill-cuttings, e.g. $\mathrm{Ba}, \mathrm{Sr}$ or THC. One exception was station $260 \% 1000 \mathrm{~m}$ (group d) which had elevated levels of $\mathrm{Ba}$ and $\mathrm{Zn}$. The groups obtained from the 1990 survey and the values of the measured environmental variables indicated that contamination was limited to stations within $1000 \mathrm{~m}$ from the platform along the $150^{\circ}$ axis, group $f$, and to $500 \mathrm{~m}$ along the $330^{\circ}$ axis, group e (e.g. for Ba; see Fig. 9). By
1993 there was an increase in contamination along the same axes, particularly along the $150^{\circ}$ axis, and significantly higher levels of $\mathrm{Ba}$ were found at all stations compared to the reference station (Table 4, Fig. 9). Again, the sampling design is inadequate to assess future trends as there are too few stations that are not contaminated in 1993. A study of the data matrix (not given) revealed that the main difference between group $a$ and b in 1993 was associated with elevated levels of $\mathrm{Ba}$ and $\mathrm{Cu}$ within group $\mathrm{b}$ compared to group a. In addition, there were also differences between these 2 station groups in sediment sorting, skewness and kurtosis. This finding differs from Valhall in 1991 and Gyda in 1993, where only variables directly related to discharge of drill-cuttings were the most important for station-group differences. At Veslefrikk in 1993 differences in the physical composition of the sediment contributed to divergent station groupings in the outermost area in that the sediments were more homogeneous, less fine skewed and platycurtic at the reference station, group a, compared to the stations in group $\mathrm{b}$. The main difference in environmental variables between these 2 groups was therefore a combination of contamination and differences in sediment characteristics.

\section{Effects of contamination}

In order to illustrate the effectiveness of multivariate analyses to detect effects of oil-related changes on the fauna, data from the same fields are used. That the observed patterns found in the fauna were related to contamination can be assessed by relating environmental data to faunal data.

Fig. 10 shows classification analyses of the fauna at Valhall in 1985, 1988 and 1991. The groupings obtained were superimposed on the MDS ordination plots (Fig. 10) and show clearly that there was a gradient with least affected fauna to the right and severely contaminated fauna to the left in the MDS plots. The resulting groups were superimposed on the sampling locations (Fig. 10). Fig. 11 shows similar analyses for the Gyda field and Fig. 12 for the Veslefrikk field. Low stress values were found in the MDS ordinations, save for Gyda in 1987, which was a baseline survey with no distinct faunal pattern expected. Also Veslefrikk 1987 is considered as a baseline survey, but had a low stress value consistent with the low number of stations, rather than an apparent faunal pattern. The low stress values indicate a more clear-cut faunal gradient compared with the baseline surveys (Fig. 5), as expected. Figs. 10 to 12 show that the area where the fauna was affected was largest at Valhall, less at Gyda, and smallest at Veslefrikk. 

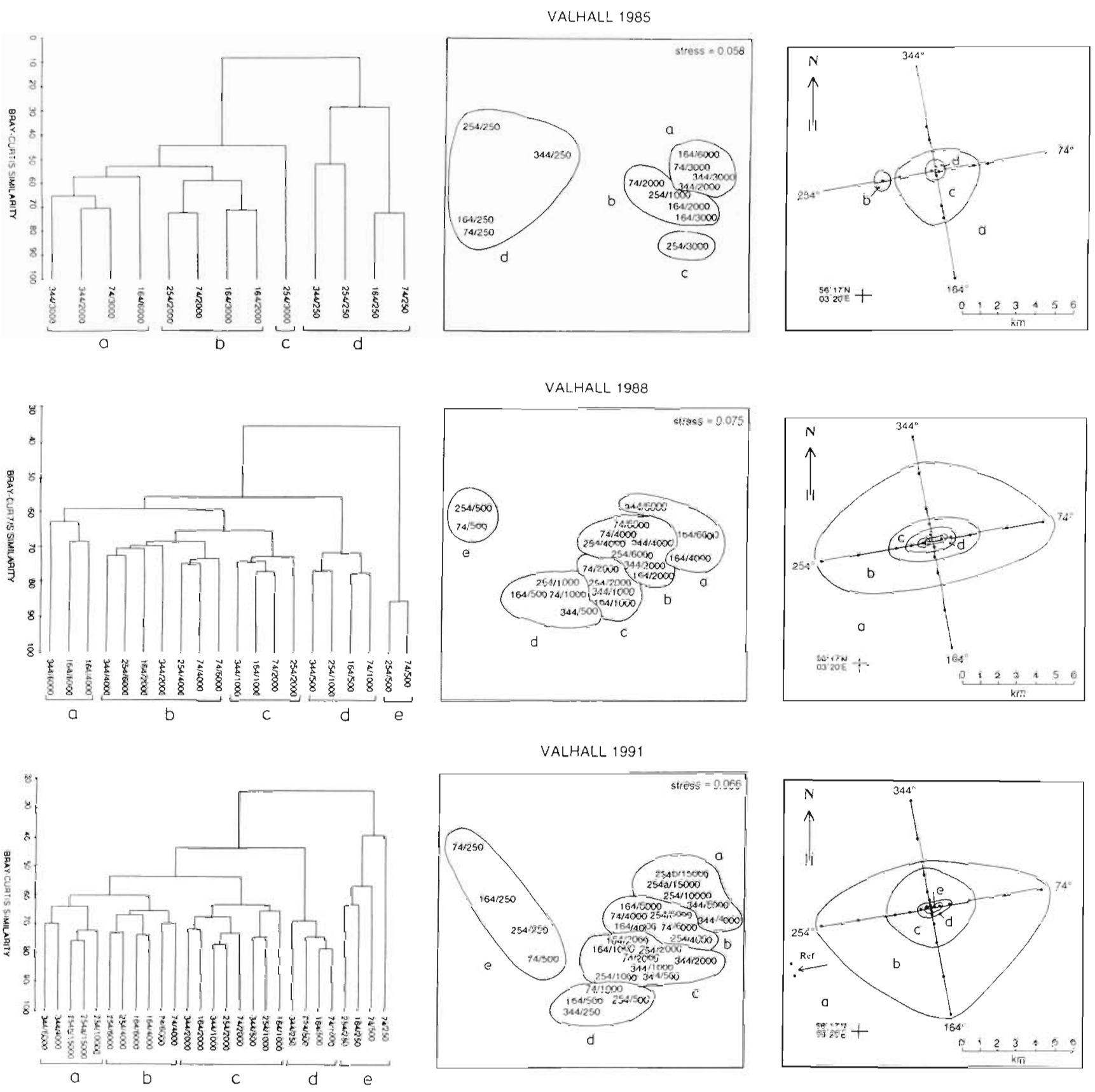

Fig. 10. Classification (left) of stations at the Valhall field according to faunal composition, MDS ordination plots (centre) with the groupings obtained from classification, and superimposition of these station groups on the original sampling stations (right) for the years 1985, 1988 and 1991

Comparison of the patterns of effects on the fauna (Figs. 10 to 12) with the patterns of contamination (Figs. 6 to 8 ) showed that there were remarkably few differences. In general the effects, with 4 categories, closely mimicked contamination. In terms of area, at Valhall 1991 only 2 contaminated stations had unaffected fauna $\left(344^{\circ} / 4000 \mathrm{~m}\right.$ and $\left.6000 \mathrm{~m}\right)$. At Gyda in 1993 only 1 station, station $225 \% 4000 \mathrm{~m}$, was contami- nated but had an unaffected fauna, whereas at Veslefrikk in 1993, 2 stations were contaminated $\left(260^{\circ} \%\right.$ $1000 \mathrm{~m}$ and $330 \% 1000 \mathrm{~m}$ ) and the fauna was unaffected. Effects of contamination thus closely followed contamination and the areas affected were nearly identical.

Table 5 illustrates results from forward selection of environmental variables in $\mathrm{CANOCO}$ and from the 

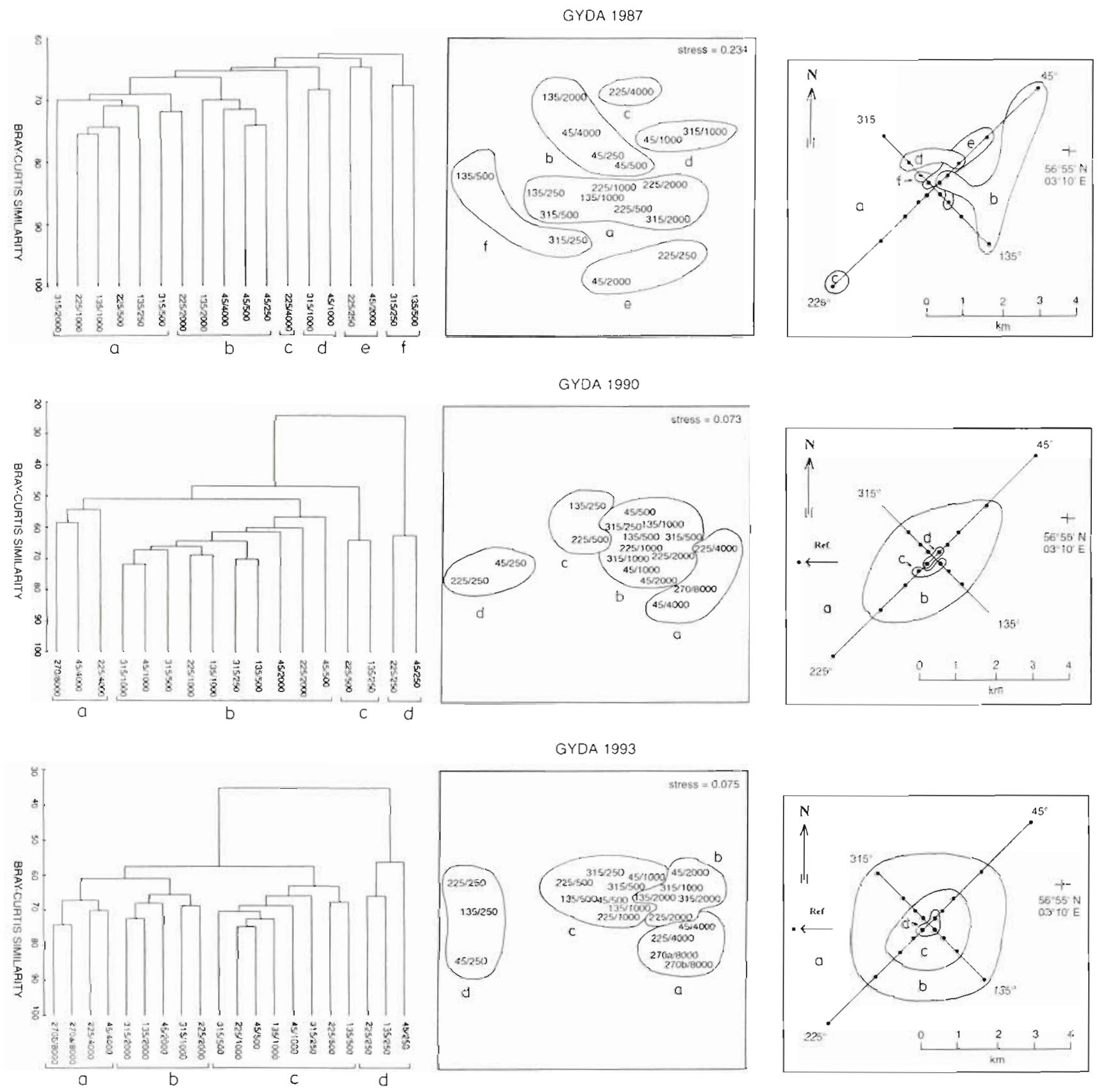

Fig. 11. As for Fig. 10, but for the Gyda field in the years 1987, 1990 and 1993

BIOENV analyses for the Valhall, Gyda and Veslefrikk fields over time. Table 5 shows clearly that whereas the fauna at Valhall was already affected by oil-related contaminants ( $\mathrm{Sr}, \mathrm{Ba}$ and $\mathrm{THC}$ ) in 1985, this was not so at Gyda and Veslefrikk. At the latter 2 fields the surveys done in 1987 correspond closely to baseline surveys with low percentage values from the forward selection in CANOCO and low $\mathrm{r}_{\mathrm{s}}$ values from BIOENV. Furthermore, the most important variables $(\mathrm{Cu}$ at Gyda and depth at Veslefrikk) were not those typically associated with oil-related effects such as $\mathrm{Sr}, \mathrm{Ba}$ and THC, as at Valhall in 1985.

In 1990 both the Gyda and Veslefrikk fields showed clear relationships to variables associated with drillcuttings (THC, Ba, and $\mathrm{Zn}$ ) and both the percentage variance values from forward selection and the $r_{5}$ values increased greatly from 1987 to 1990 at the 2 fields, indicating clear relationships between faunal composition and sediment contamination in 1990. In 1993 the Gyda field had variable loadings comparable to those 

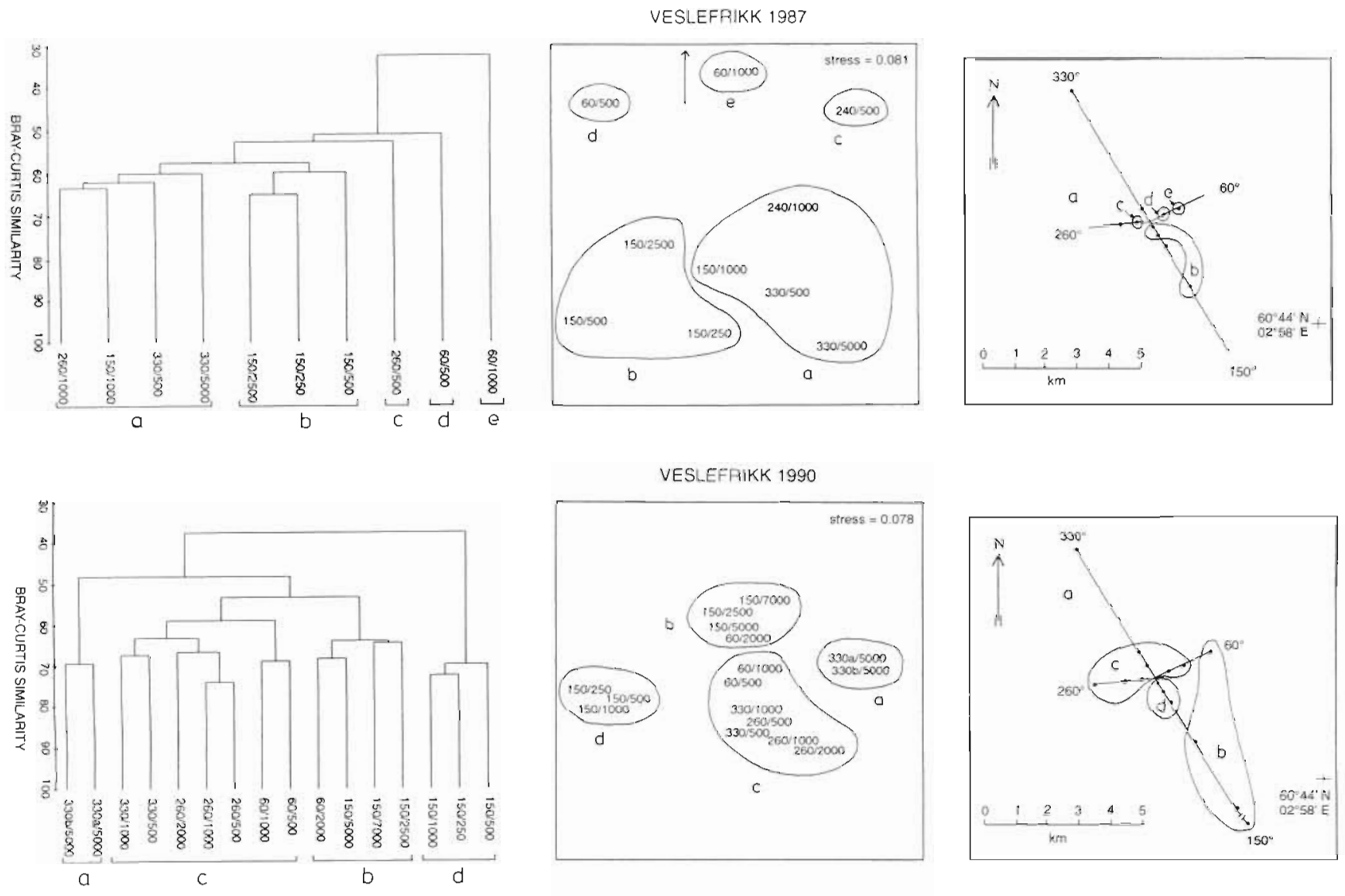

VESLEFRIKK 1993
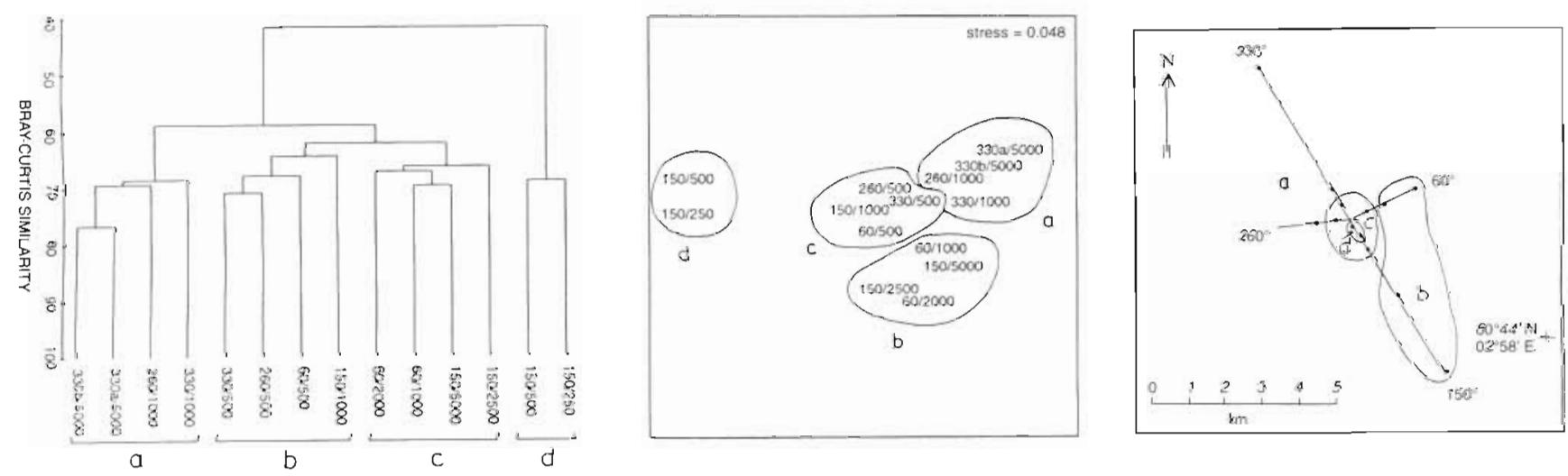

Fig 12. As for Fig. 10, but for the Veslefrikk field in the years 1987, 1990 and 1993

of Valhall in 1988 and Veslefrikk in 1990 with THC, $\mathrm{Ba}$ and $\mathrm{Sr}$ as the most important variables in both CANOCO and BIOENV

In 1991 at Valhall (Table 5a) the CANOCO forward selection suggested TOC, $\mathrm{Zn}, \mathrm{Pb}, \mathrm{THC}$ and $\mathrm{Sr}$ as the most important variables related to the fauna whereas BIOENV ranked the variables: THC, Sr, $\mathrm{Zn}, \mathrm{Ba}$ and TOC. Overall the same 5 variables were ranked significantly, and all showed a high degree of correlation with the faunal composition. This shows that the differences between methods were small, and that in an area clearly affected by drill-cuttings all the variables related to the discharges were highly intercorrelated. In 1993 at Veslefrikk (Table 5c) the key variables associated with faunal changes were the heavy metals $\mathrm{Cd}$, $\mathrm{Cu}, \mathrm{Zn}, \mathrm{Pb}$ and the TOC in CANOCO and $\mathrm{Fe}, \mathrm{Cd}, \mathrm{Cu}$, $\mathrm{Pb}$ and $\mathrm{Zn}$ in BIOENV. Of the 5 most significant only TOC and $\mathrm{Fe}$ were not selected in both methods, again 
Table 5. Relationship between environmental variables and fauna using forward selection in CANOCO (left) and BIOENV in PRIMER (right) for non-baseline surveys (except for Gyda in 1987 and Veslefrikk in 1987, which are baseline surveys). Explanation as in Table 3

\begin{tabular}{|c|c|c|c|c|c|c|c|c|c|c|c|}
\hline \multicolumn{2}{|c|}{$\begin{array}{r}\text { (a) Valhall } \\
1985\end{array}$} & \multicolumn{2}{|c|}{1988} & \multicolumn{2}{|r|}{1991} & \multicolumn{2}{|c|}{1985} & \multicolumn{2}{|c|}{1988} & \multicolumn{2}{|c|}{1991} \\
\hline $\mathrm{Sr}$ & $43.8 \% \cdots$ & THC & $41.6 \% \cdots$ & TOC & $33.8 \% \cdots$ & $\mathrm{Sr}$ & $r=0.640$ & $\mathrm{Ba}$ & $r=0.662$ & THC & $r=0.750$ \\
\hline $\mathrm{Ba}$ & $41.5 \%$ & $\mathrm{Ba}$ & $37.1 \%$ & $\mathrm{Zn}$ & $33.4 \% \cdots$ & $\mathrm{Ba}$ & $r=0.618$ & $\mathrm{THC}$ & $\mathrm{r}=0.652$ & $\mathrm{Sr}$ & $r=0.753$ \\
\hline $\mathrm{THC}$ & $38.8 \%$ & $\mathrm{Sr}$ & $37.1 \% \cdots$ & $\mathrm{Pb}$ & $31.7 \% \cdots$ & $\mathrm{Zn}$ & $r=0.588$ & $\mathrm{Sr}$ & $r=0.554$ & $\mathrm{Zn}$ & $r=0.677$ \\
\hline $\mathrm{Zn}$ & $38.2 \% \cdot$ & $\mathrm{Fe}$ & $35.4 \%$ & $\mathrm{THC}$ & $31.3 \% \cdots$ & THC & $r=0.523$ & $\mathrm{Zn}$ & $r=0.463$ & $\mathrm{Ba}$ & $r=0.675$ \\
\hline \multirow[t]{2}{*}{$\mathrm{Fe}$} & $33.2 \% \cdots$ & $\mathrm{Pb}$ & $34.2 \% \cdots$ & $\mathrm{Sr}$ & $30.9 \% \cdots$ & & $r=0.484$ & $\mathrm{~Pb}$ & $r=0.343$ & TOC & $r=0.655$ \\
\hline & & & & & & \multicolumn{2}{|c|}{$\begin{array}{l}\text { Max corr.: } \\
\text { Sr, Ba, THC, <63 } \mu \mathrm{m} \\
\mathrm{r}_{\mathrm{s}}=0.727\end{array}$} & \multicolumn{2}{|c|}{$\begin{array}{l}\text { Max. corr.. } \\
\mathrm{Ba}_{\text {, THC }} \\
\mathrm{r}_{\mathrm{s}}=0.693\end{array}$} & \multicolumn{2}{|c|}{$\begin{array}{l}\text { Max corr: } \\
\text { THC, } \mathrm{Ba}, \text { TOC } \\
\mathrm{r}_{\mathrm{s}}=0.833\end{array}$} \\
\hline \multicolumn{12}{|c|}{ (b) Gyda } \\
\hline \multicolumn{2}{|c|}{1987} & \multicolumn{2}{|c|}{1990} & \multicolumn{2}{|r|}{1993} & \multicolumn{2}{|c|}{1987} & \multicolumn{2}{|c|}{1990} & \multicolumn{2}{|c|}{1993} \\
\hline $\mathrm{Cu}$ & $14.7 \% \cdots$ & $\mathrm{Cu}$ & $38.1 \% \cdots$ & THC & $39.7 \% \cdots$ & $\mathrm{Cu}$ & $r=0.312$ & $\mathrm{Ba}$ & $I=0.583$ & $\mathrm{Ba}$ & $r=0.679$ \\
\hline Sr & $9.4 \% \cdots$ & THC & $37.7 \% \cdots$ & $\mathrm{Ba}$ & $39.2 \% \cdots$ & $\operatorname{Md} \varphi$ & $r=0.039$ & THC & $r=0.535$ & $\mathrm{THC}$ & $r=0.677$ \\
\hline $\mathrm{Zn}$ & $8.4 \% \cdots$ & $\mathrm{Zn}$ & $37.2 \% \cdots$ & $\mathrm{SI}$ & $39.2 \% \cdot \cdot$ & & $r=0.014$ & & $I=0.531$ & & $r=0.599$ \\
\hline $\operatorname{Md} \varphi$ & $7.3 \%{ }^{\mathrm{ns}}$ & Sorting & $34.5 \% \cdots$ & $\mathrm{Zn}$ & $37.5 \% \cdots$ & Sorting & $r=-0.075$ & $\mathrm{Zn}$ & $r=0.395$ & Kurto & $\mathrm{sr}=0.485$ \\
\hline \multirow[t]{2}{*}{ TOC } & $6.3 \%{ }^{\mathrm{ns}}$ & $\mathrm{Ba}$ & $33.6 \%$ & $\mathrm{Cu}$ & $37.0 \% \cdots$ & $\mathrm{Pb}$ & $r=-0.011$ & Sorting & $I=0.341$ & $\mathrm{Cu}$ & $r=0.443$ \\
\hline & & & & & & \multicolumn{2}{|c|}{$\begin{array}{l}\text { Max. corr.: } \\
\mathrm{Cu} \\
r_{\mathrm{s}}=0.312\end{array}$} & \multicolumn{2}{|c|}{$\begin{array}{l}\text { Max. corr.: } \\
\mathrm{Ba}, \mathrm{Cu} \\
\mathrm{r}_{\mathrm{s}}=0.687\end{array}$} & \multicolumn{2}{|c|}{$\begin{array}{l}\text { Max. corr.: } \\
\text { Ba, THC, Kurtosis } \\
\mathrm{r}_{\mathrm{s}}=0.773\end{array}$} \\
\hline \multicolumn{12}{|c|}{ (c) Veslefrikk } \\
\hline \multicolumn{2}{|c|}{1987} & \multicolumn{2}{|c|}{1990} & \multicolumn{2}{|r|}{1993} & \multicolumn{2}{|c|}{1987} & \multicolumn{2}{|c|}{1990} & \multicolumn{2}{|c|}{1993} \\
\hline Depth & $19.4 \% \cdots$ & $\mathrm{THC}$ & $38.0 \% \cdots$ & C & $40.2 \% \cdots$ & Depth & $r=0.371$ & $\mathrm{Zn}$ & $r=0.623$ & $\mathrm{Fe}$ & $r=0.710$ \\
\hline$<63 \mu \mathrm{m}$ & $18.6 \%$ & $\mathrm{Ba}$ & $37.4 \% \cdots$ & $\mathrm{Cu}$ & $40.2 \% \cdots$ & $<63 \mu \mathrm{m}$ & $I=0.018$ & $\mathrm{Cr}$ & $r=0.587$ & $\mathrm{C}$ & $r=0.697$ \\
\hline $\operatorname{Md} \varphi$ & $16.3 \%{ }^{\mathrm{ns}}$ & $\mathrm{Zn}$ & $35.6 \% \cdots$ & $\mathrm{Zn}$ & $40.2 \% \cdots$ & $\operatorname{Md} \varphi$ & $r=-0.015$ & $\mathrm{Ba}$ & $r=0.549$ & $\mathrm{Cu}$ & $r=0.608$ \\
\hline Sorting & $15.5 \%{ }^{\mathrm{ns}}$ & $\mathrm{Cr}$ & $35.0 \% \cdots$ & TOC & $39.0 \% \cdots$ & Sorting & $\mathrm{r}=-0.056$ & $\mathrm{Cu}$ & $r=0.436$ & $\mathrm{~Pb}$ & $r=0.556$ \\
\hline \multirow[t]{2}{*}{$\mathrm{THC}$} & $11.6 \%{ }^{\text {ns }}$ & $\mathrm{Fe}$ & $33.1 \% " \cdot$ & $\mathrm{Pb}$ & $39.0 \% \cdots$ & TOC & $\mathrm{r}=-0.065$ & $\mathrm{Fe}$ & $r=0.431$ & $\mathrm{Zn}$ & $\mathrm{r}=0.549$ \\
\hline & & & & & & \multicolumn{2}{|c|}{$\begin{array}{l}\text { Max. corr: } \\
\text { Depth } \\
r_{s}=0.371\end{array}$} & \multicolumn{2}{|c|}{$\begin{array}{l}\text { Max. corr: } \\
\mathrm{Ba}, \mathrm{Fe}, \mathrm{THC} \\
\mathrm{I}_{\mathrm{s}}=0.733\end{array}$} & \multicolumn{2}{|c|}{$\begin{array}{l}\text { Max. corr.: } \\
\text { Fe, TOC } \\
\mathrm{r}_{\mathrm{s}}=0.765\end{array}$} \\
\hline
\end{tabular}

indicating consistency in the results. The percentage values in CANOCO and correlation coefficients in BIOENV were also high, both indicating clear impact from cuttings discharges. Due to small differences and high degree of intercorrelation between the measured environmental variables the rank orders in 1993 varied randomly. The results in Table $5 \mathrm{c}$ also suggest that at Veslefrikk over time (1990 to 1993) there was a change in indicators of effect from initially $\mathrm{Ba}$ and THC to heavy metals presumably because the oil was degraded but the barite continued to spread.

To illustrate that the trends found at the Valhall, Gyda and Veslefrikk fields after several years of discharges of oil-based drill-cuttings are general ones the results from similar analyses of data from Oseberg South 1989, Gullfaks A 1989 and Hod 1991 are shown in Table 6. Development drilling began at Oseberg $\mathrm{S}$ and Gullfaks A in 1985 and at Hod in 1982. Table 6 shows clearly that the 'best' explanatory variables also at these fields were $\mathrm{THC}, \mathrm{Ba}$ and $\mathrm{Sr}$, all related to cuttings discharges from the platforms.

Fig. 13 shows results from correlation-based PCA analyses of the environmental variables at the Veslefrikk field in 1987, 1990 and 1993. In 1987, with no contamination, there was little positive correlation between the environmental variables (arrows representing the individual environmental variables do not point in the same direction) except for the sediment parameters median grain size $(\mathrm{Md} \varphi)$, sorting and silt-clay content $(<63 \mu \mathrm{m})$ and $\mathrm{Sr}$ and $\mathrm{Cr}$. After $3 \mathrm{yr}$ of discharge, the measured variables tend to be more positively correlated over time. By 1993 the heavy metals are strongly intercorrelated with each other and with the content of THC, shown by these arrows having a uniform direction.

Despite the fact that many of the results presented are based on biological data, so far there has been little mention of the faunal characteristics. One question 
Table 6. Relationships between environmental variables and fauna for 3 non-baseline surveys using forward selection in CANOCO (left) and BIOENV in PRIMER (right). Explanation as in Table 3

\begin{tabular}{|c|c|c|c|c|c|c|c|c|c|c|c|}
\hline \multicolumn{2}{|c|}{ Oseberg S 1989} & \multicolumn{2}{|c|}{ Gullfaks A 1989} & \multicolumn{2}{|c|}{ Hod 1991} & \multicolumn{2}{|c|}{ Oseberg S 1989} & \multicolumn{2}{|c|}{ Gullfaks A 1989} & \multicolumn{2}{|c|}{ Hod 1991} \\
\hline $\mathrm{Ba}$ & $15.7 \% \cdots$ & THC & $29.9 \% \cdots$ & THC & $16.8 \% \cdots$ & $\mathrm{Ba}$ & $r=0.340$ & THC & $r=0.501$ & $\mathrm{Ba}$ & $r=0.415$ \\
\hline THC & $14.5 \% \cdots$ & $\mathrm{Ba}$ & $25.9 \% \cdots$ & $\mathrm{Ba}$ & $16.0 \% \cdots$ & THC & $r=0.338$ & $\mathrm{Ba}$ & $r=0.492$ & $\mathrm{Sr}$ & $r=0.373$ \\
\hline $\mathrm{Sr}$ & $12.2 \% \cdot$ & $\mathrm{Cu}$ & $24.2 \% \cdots$ & $\mathrm{Sr}$ & $15.2 \% \cdots$ & $\mathrm{Sr}$ & $r=0.191$ & $\mathrm{Cu}$ & $r=0.389$ & THC & $r=0.322$ \\
\hline Depth & $6.5 \%{ }^{n s}$ & $\mathrm{Zn}$ & $22.5 \% \cdots$ & $\mathrm{Pb}$ & $14.4 \% \cdots$ & Depth & $r=0.073$ & $\mathrm{Fe}$ & $r=0.292$ & $\mathrm{Cd}$ & $r=0.321$ \\
\hline \multirow[t]{2}{*}{$<63 \mu \mathrm{m}$} & $6.1 \%$ ns & $\mathrm{Pb}$ & $22.5 \%$ & $\mathrm{Cd}$ & $12.0 \% \cdots$ & & $r=0.039$ & $\mathrm{Zn}$ & $r=0.292$ & $\mathrm{~Pb}$ & $r=0.291$ \\
\hline & & & & & & \multicolumn{2}{|c|}{$\begin{array}{l}\text { Max. corr.: } \\
\text { Ba, THC, Depth } \\
\mathrm{I}_{\mathrm{s}}=0.373\end{array}$} & \multicolumn{2}{|c|}{$\begin{array}{l}\text { Max corr: } \\
\text { THC, } \mathrm{Ba}, \mathrm{TOC} \\
\mathrm{r}_{\mathrm{s}}=0.571\end{array}$} & \multicolumn{2}{|c|}{$\begin{array}{l}\text { Max. corr.: } \\
\mathrm{Ba}_{1} \mathrm{Sr}, \mathrm{THC}, \mathrm{Cd}, \\
\mathrm{Zn}, \mathrm{Md} \varphi \\
\mathrm{r}_{\mathrm{s}}=0.552\end{array}$} \\
\hline
\end{tabular}
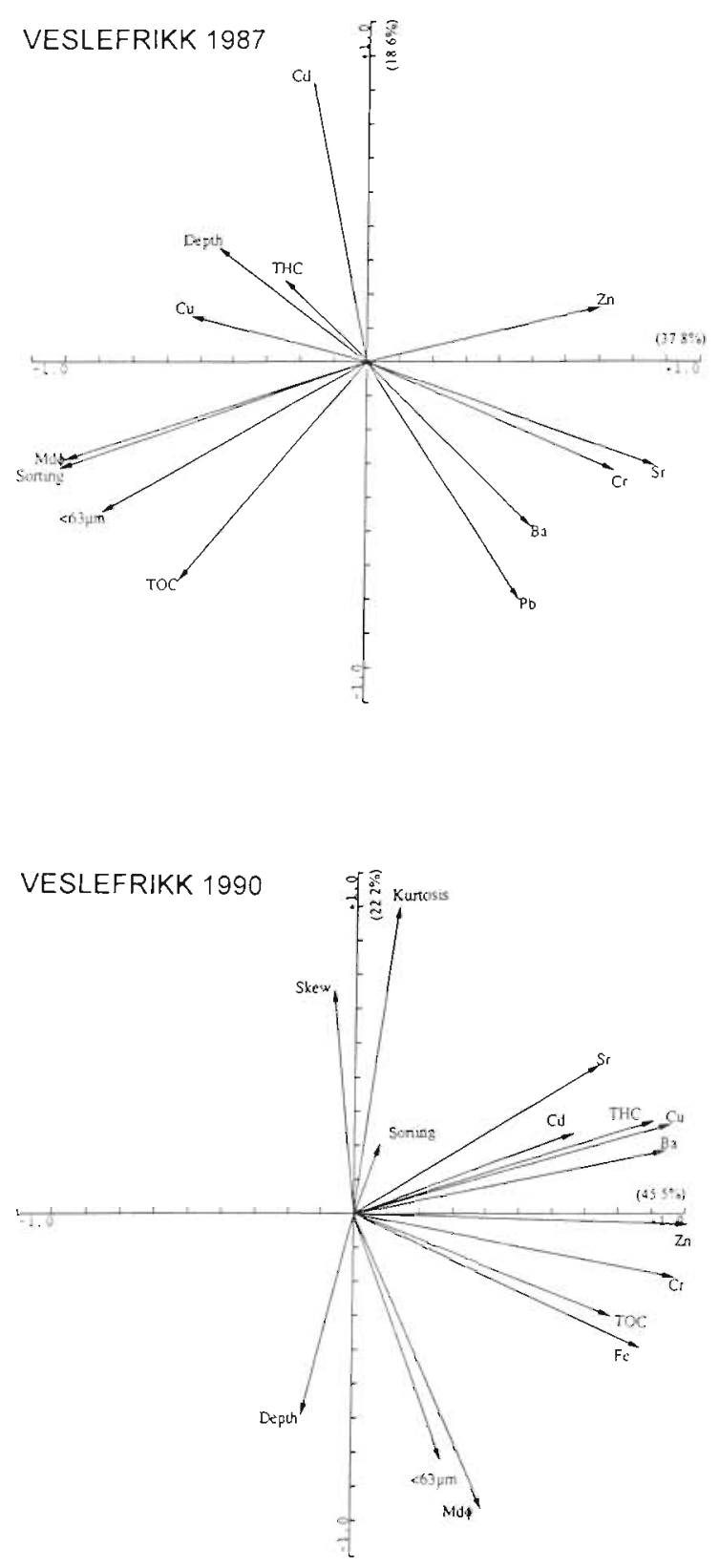

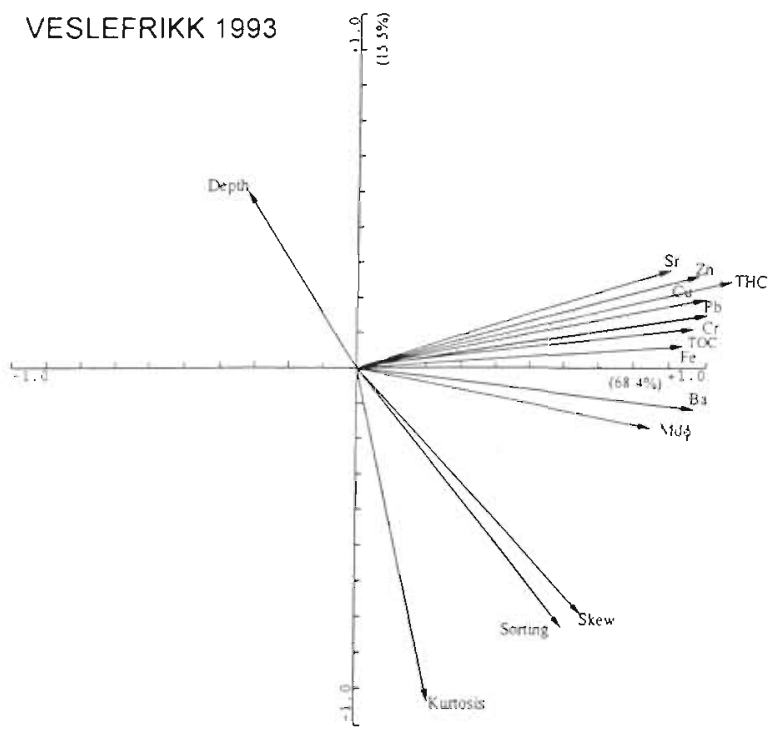

Fig. 13. Correlation between environmental variables, as shown by a PCA ordination plot of the environmental variables measured at the Veslefrikk field in 1987, 1990 and 1993. Arrows that point in the same direction indicate positively correlated variables, perpendicular arrows indicate lack of correlation and arrows pointing in the opposite direction indlcate negatively correlated variables. In 1987 the explained variance along Axis 1 and 2 was $37.8 \%$ and $18.6 \%$, respectively. The corresponding values in 1990 were $45.5 \%$ and $22.2 \%$, and in $1993,684 \%$ and $15.5 \%$, respectively

that is often raised is are there species that characterise the initial stages of effects of pollution, and are these species similar over large geographical scales, i.e. universal indicators of initial disturbance? Using the SIMPER program in PRIMER the species that characterise the difference between the unaffected group a and the just-affected group b were determined. Table 7 shows just the 3 species highest ranked in SIMPER that show highest reduction in abundance from the uncontaminated to the just-contaminated groups of stations (although there are in fact many more than 3 species 


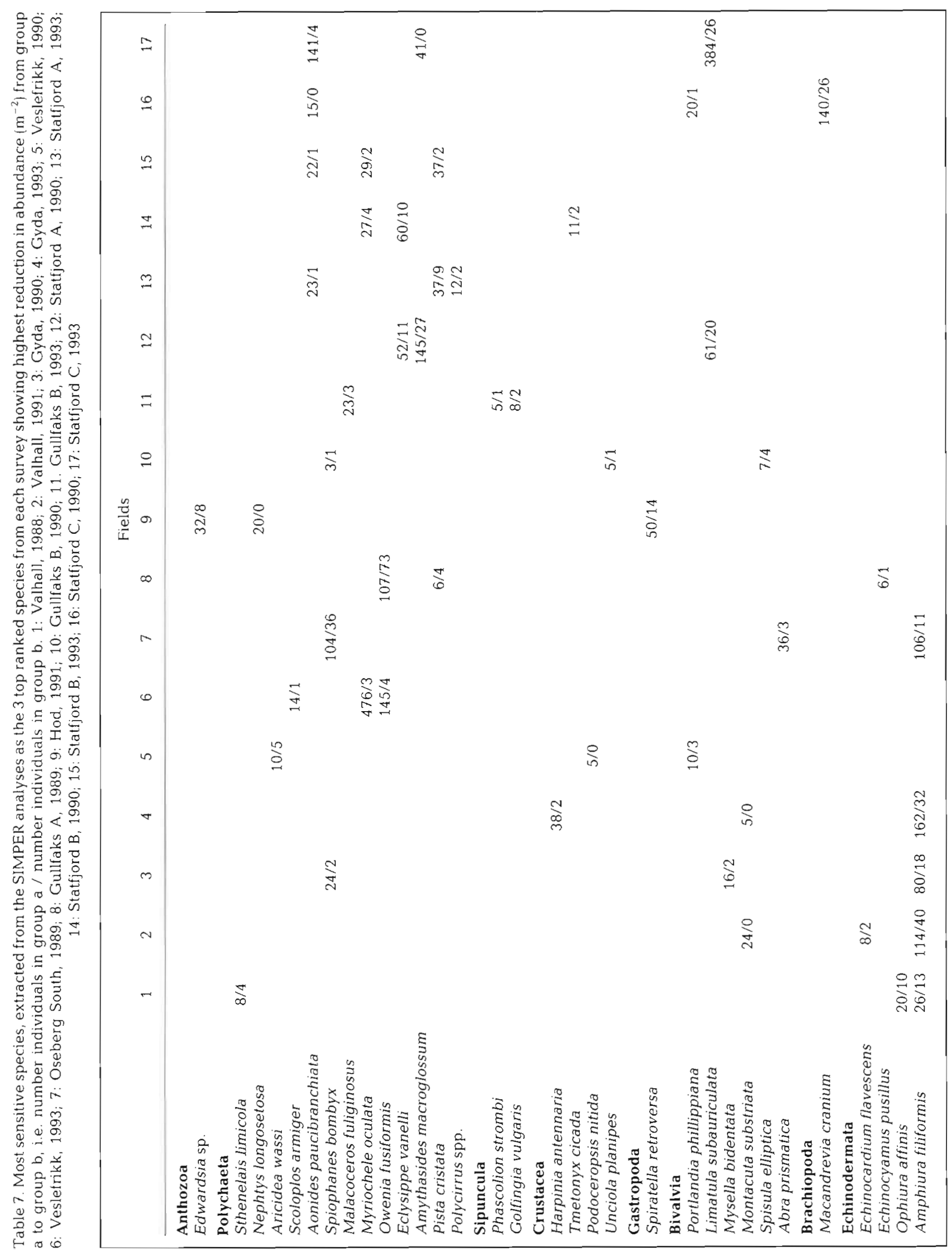




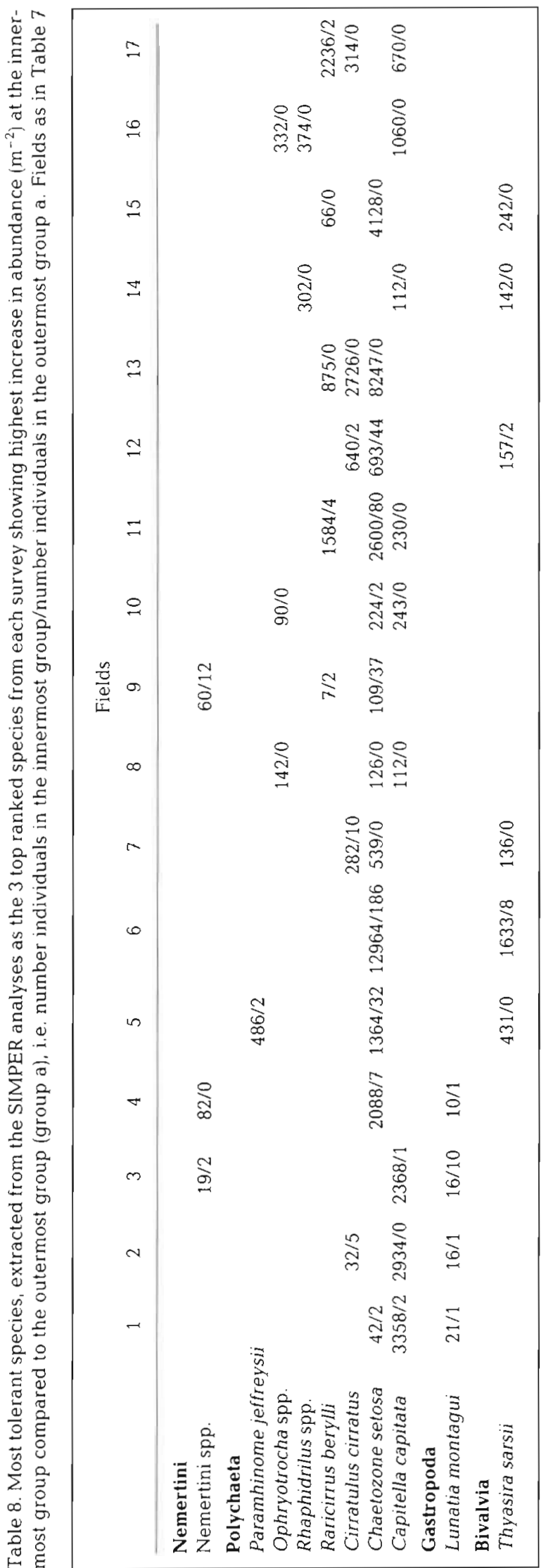

that characterise the difference between these 2 groups). The table shows that there were few species that were consistently important as indicators of initial effects within the southern Norwegian continental shelf. The analyses also rank species showing increased abundances from group a to b, but similarly showed no consistent pattern.

Table 8 shows data obtained from SIMPER analyses showing species that characterise the differences between the highly polluted group close to the platforms and the unpolluted, outermost group a. Here there were many species that showed consistent patterns indicating that the pollutant tolerant species were more ubiquitous within this part of the North Sea.

\section{DISCUSSION}

In relation to chemical discharges often no distinction is made between contamination (raised levels of the chemical compared with natural background levels) and the effects of this contamination; both are called pollution. The UN Group of Experts on Scientific Aspects of Marine Environmental Protection (GESAMP) distinguishes between raised concentrations of chemicals, called contamination, and the effects of that contamination on biota, called pollution. Here we examine first contamination and then pollution from oil-related discharges.

The primary source of environmental disturbance around oil and gas platforms in the Norwegian sector has been the discharge of drill-cuttings containing oil. However, the amounts of oil and oil-based cuttings discharged have decreased in recent years (Fig. 1). At the 3 main fields analysed here, discharges of oil-based drill-cuttings show that the Valhall and Gyda fields received far more cuttings than at Veslefrikk (Table 9). In addition, of the 3 fields, the Valhall field has a longer history of oil activities. Thus one might expect that effects were more severe at Valhall than Gyda and Veslefrikk.

Little use has been made in previous studies of both physical and chemical data in the analysis of the patterns ensuing from oil-related activities. Here we have used several multivariate techniques applied to physical and chemical data. Baseline data show no clear patterns with a 'shotgun' type scatter of stations (Figs. 4 \& 5) and no clear correlation between any of the environmental variables and the fauna (Table 3 ), save for Snorre where depth was important, and Mime where TOC was correlated with the pattern of stations.

The patterns of development of contamination were clearly shown at all 3 fields studied, Valhall (Fig. 6), Gyda (Fig. 7) and Veslefrikk (Fig. 8). Plots of mean values of $\mathrm{Ba}$ and $95 \%$ confidence intervals (Fig. 9) clearly 
demonstrated the relation between drill-cuttings discharges and station groupings. Significantly higher $\mathrm{Ba}$ values were found between the justcontaminated station groups (group b) compared to levels at a few of the outermost stations and the reference stations (group a). Inspection of the environmental data-matrices also revealed that other compounds related to cuttings discharges, such as $\mathrm{Sr}, \mathrm{Cu}, \mathrm{Cd}$ and $\mathrm{THC}$, often showed elevated concentrations in the group $b$ stations compared to group a

It might be argued that since only the reference stations were different from the just-affected group b, one can only say that this group of stations differed from the reference and this may not be due to increased contamination. However, Figs, 6 to 8 show a gradual increase in the area of contamination, displayed as rings around the platforms, consistent with the argument that only the reference stations were uncontaminated after 6 to 9 yr of discharge. Fig. 9 shows that the group a stations at Valhall and Gyda in 1990 and 1993 and Veslefrikk in 1993 had significantly lower levels of $\mathrm{Ba}$ than the remaining station groups. If one accepts contamination has been shown out to a $6000 \mathrm{~m}$ radius at Valhall this gives an area of at least $100 \mathrm{~km}^{2}$ contaminated. For the Gyda field in 1993 there were samples taken only out to $2000 \mathrm{~m}$ on 2 axes $\left(135^{\circ}\right.$ and $315^{\circ}$ ) and the contamination extends to $>2000 \mathrm{~m}$ along these axes and $>4000 \mathrm{~m}$ on the $225^{\circ}$ axis. Thus the area contaminated is probably in excess of $15 \mathrm{~km}^{2}$. At Veslefrikk in 1993 the contamination was ellipsoidal stretching along the main current direction out to the furthest point measured (5 km along the $150^{\circ}$ axis), and affected an area of at least $10 \mathrm{~km}^{2}$. These findings substantiate the unpublished data referred to in the GESAMP report (1993) that contamination covers large areas of sea-bed.

Davies et al. (1984) have suggested that there is a gradual movement of cuttings away from the platforms and that during this movement biodegradation of THC takes place. This was also shown at the Gyda, Valhall and Veslefrikk fields. After cessation, or almost cessation, of drill-cuttings discharges reduced THC concentrations were found in the outer areas. Also Ba and many of the associated metals in the sediments showed a decrease in concentration subsequent to cessation of discharges. The observed decrease in concentrations of $\mathrm{Ba}$ and associated heavy metals in the outermost areas at Valhall in 1991 and Gyda in 1993 may indicate resuspension and a continuous and wide dispersal of these elements. Despite reductions in concentrations of both THC and metals following cessation of cuttings an obvious enlargement of the total area of biological impact was observed. This indicates that there are other compounds in the discharges, that were not measured, that have a negative ecological impact.

Some workers have suggested that once discharge of drill-cuttings has stopped, improvement of environmental conditions will occur almost immediately (e.g. Levell 1987). Davies et al. (1989) argue that recovery and recolonization of the transition zone begins within 1 to $2 \mathrm{yr}$. They suggest that following a degradation of the oil hydrocarbons, the biological transition zone begins to move inwards, despite some outward redistribution of drill-cuttings. Our data show that this is not the case; there is a continuous increase in the total area affected even several years after cessation of cuttings discharges; see Table 9 and Figs. 10 to 12 for the Valhall, Gyda and Veslefrikk fields.

Our data from these 3 fields clearly illustrate that the sampling design is now inadequate to assess the degree of contamination as there are too few reference stations in the unaffected area. There is thus a need for a revision of the sampling strategy, especially since the present design does not take neighbouring fields into account. Now that contamination can be demonstrated to cover $100 \mathrm{~km}^{2}$ around 1 field it is likely that many adjacent fields show overlapping contamination.

The development of patterns showing effects on the fauna were consistent within fields. Baseline surveys show that there was no consistent pattern between the measured environmental variables and the fauna, as assessed by 2 different methods, forward selection in CANOCO and the BIOENV program in PRIMER (Table 3). At the Snorre field, depth was a significant factor in both methods and at Mime, sediment content of TOC, whereas at the other fields different variables correlated with the fauna (Table 3). The development of contamination and its correlation with effects on the fauna showed that the effects were associated predominantly with THC, Ba and Sr (Table 5).

When/where pollution was severe, e.g. at Valhall in 1991 and Gyda in 1993, it was THC, Ba, Sr and heavy metals associated with the barite component of the drill-cuttings which showed the clearest correlation with the patterns in the fauna (Table 5). As contamination developed, the measured environmental variables became more intercorrelated (Fig. 13, right hand side). 
However, correlations between effects on the fauna and physical and chemical variables do not necessarily show cause and effect relationships. Furthermore, one cannot be sure that an apparently explanatory variable was not a proxy for an unmeasured variable that really was causal.

As Dixon (1987) has pointed out, long-term comparative studies using experimental systems such as mesocosms are needed to determine cause and effect relationships. Whilst we agree with this, at the same time the recent change to water-based drilling muds on the Norwegian continental shelf is in itself a fieldexperiment. A comparison of contamination and biological effects between areas where oil-based mud and areas where only water-based mud have been used should give indications of which components result in adverse effects. Preliminary results (unpubl.) from monitoring surveys at fields where only water-based mud were employed clearly indicate less contamination and biological impact, compared to the results reported here. This suggests that the main adverse effects were related to the oil-components in the mud, but further investigations are necessary to establish the relationships. Yet the fact that more barite is now being used, and that the barite contains high quantities of heavy metal impurities, suggests the need of further studies.

Acute toxicity studies, however, suggest that barite is not particularly toxic (e.g. Cabrera 1971, George 1975). Starczak et al. (1992) showed that in laboratory tests there were no deleterious effects on faecal pellet production, growth and tube production in the polychaete Mediomastus ambiseta at realistic sediment concentrations of barite. However, in laboratory studies on development of an estuarine community Tagatz \& Tobia (1978) found that significantly fewer individuals and species colonised sand covered by barite compared with controls. Polychaetes were particularly affected. The study of Tagatz \& Tobia was on a community comprising 59 species rather than on a single species as in the acute tests and $M$. ambiseta study. It is likely that the application of multivariate techniques to complex community data, as done here with usually over 150 species per field studied (see Table 2), will reveal far more subtle effects than toxicity studies.

Another important finding was that the degree of contamination, as defined by multivariate analyses of physical and chemical data, and the degree of effects were closely similar and patterns were repeated at the different fields (comparison of Figs. 6 to 8 and 10 to 12). The spatial extent of effects was only slightly less than that of contamination. This illustrates that (1) the methods used are highly sensitive and (2) the effects are traceable to a larger area than has been assessed previously.
The most obvious question to ask is do the effects found relate to the amount of drill-cuttings discharged? The distance to which the fauna was affected along the major axis was plotted against the amount of drillcuttings discharged (Fig. 14). There was no correlation ( $r=0.328, n=10, p>0.05)$ between input of drillcuttings and the border of affected fauna. For example, Statfjord C in 1990 did not show the largest extent of affected fauna despite having the largest amount of cuttings discharged. Other factors than mere amounts of drill-cuttings are clearly important, such as the type of mud used, the particle size of the cuttings, hydrographic conditions, depth, etc., all of which varied between fields. In addition, multivariate analyses are better able to detect effects of contamination in areas where environmental variables (e.g. depth and sediment characteristics) and faunal distribution are homogeneous. This is the probable explanation for the fact that there were clear patterns at Valhall and Gyda, but less clear patterns at Statfjord $C$ which has been subjected to higher loads of drill-cuttings, but has a more heterogeneous sediment and probably stronger bottom currents

One can obtain a scaling of pollution using the effects on the fauna. Table 10 shows the data where the criterion used was the reduction in number of species from the background (uncontaminated) stations compared with the $500 \mathrm{~m}$ stations along the main current direction. In this analysis, Statfjord C in 1990 was the most affected field, followed by Valhall 1991. Interestingly, in 1993 Statfjord C was less affected with a higher number of species at the $500 \mathrm{~m}$ station than in 1990. This was also the case for Statfjord A and B and Gullfaks B which were all less affected in 1993 compared with 1990. This suggests that there has been an improvement due to abatement of discharges at these fields in recent years, measured as an increased num-

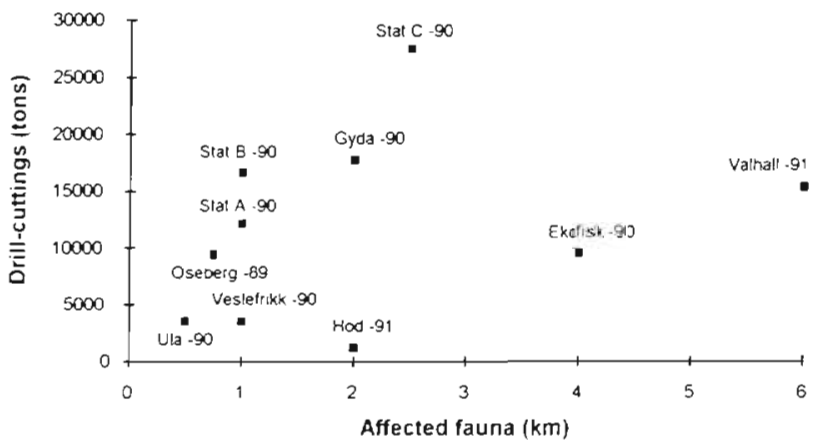

Fig. 14. Relationships between maximum distance from the platforms of measured faunal effects and the amount of oilbased drill cuttings discharged. Data from separate investigations at the Ula and the Ekofisk field, both in 1990, are also included 
ber of species compared to background values.

Here, using multivariate techniques the areas of effects were far larger than could be found using diversity indices. Fig. 15 shows values for ShannonWiener diversity $\left(H^{\prime}\right)$ plotted against sediment content of $\mathrm{Ba}$ (Fig. 15a) and THC (Fig. 15b) as indicators of contamination, at the $500 \mathrm{~m}$ stations along the primary current direction axis. Values of diversity, $\mathrm{Ba}$ and THC are given as ratios of the observed value divided by the background value, which allows comparisons to be made taking into account the natural differences in diversity (cf. Heip et al. 1992) and levels of $\mathrm{Ba}$ and THC within the areas studied and any slight differences in methodology. The Shannon-Wiener diversity indices showed wide scatter and no clear gradient of effects whereas an even simpler measure, number of species (Fig. 15c, d), showed a significant decrease with increased levels of cont-
Table 10. Ranking of non-baseline fields according to reduction in number of species $(\mathrm{N})$ at the $500 \mathrm{~m}$ station along the prevailing current direction compared to control(s) and/or unaffected stations ( $N 500 \mathrm{~m}$ station/mean $\mathrm{N}$ control and/or unaffected stations). -: increase

\begin{tabular}{|lcccc|}
\hline Field & $\begin{array}{c}\text { N at } \\
500 \mathrm{~m} \\
\text { station }\end{array}$ & $\begin{array}{c}\text { Mean N at } \\
\text { control and/or } \\
\text { unaffected } \\
\text { station(s) }\end{array}$ & $\begin{array}{c}\text { N } 500 \mathrm{~m} / \mathrm{mean} \\
\text { N control } \\
\text { and/or } \\
\text { unaffected } \\
\text { station(s) }\end{array}$ & $\begin{array}{c}\text { \% reduction } \\
\text { in } \mathrm{N}\end{array}$ \\
\hline Statfjord C, 1990 & 25 & 84 & 0.30 & 70 \\
Valhall, 1991 & 24 & 56 & 0.42 & 58 \\
Statfjord C, 1993 & 49 & 112 & 0.44 & 56 \\
Valhall, 1988 & 21 & 39 & 0.54 & 46 \\
Gyda, 1990 & 42 & 66 & 0.63 & 37 \\
Veslefrikk, 1993 & 61 & 86 & 0.71 & 29 \\
Gyda, 1993 & 43 & 59 & 0.72 & 28 \\
Valhall, 1985 & 24 & 33 & 0.72 & 28 \\
Gullfaks A, 1989 & 53 & 79 & 0.73 & 27 \\
Statfjord A, 1990 & 62 & 76 & 0.82 & 18 \\
Statfjord B, 1990 & 60 & 72 & 0.83 & 17 \\
Gullfaks B, 1990 & 39 & 46 & 0.85 & 15 \\
Oseberg S, 1989 & 34 & 40 & 0.85 & 15 \\
Hod, 1991 & 50 & 58 & 0.86 & 11 \\
Statfjord A, 1993 & 77 & 87 & 0.89 & 2 \\
Veslefrikk, 1990 & 80 & 89 & 0.90 & - \\
Statfjord B, 1993 & 84 & 86 & 0.98 & 10 \\
Gullfaks B, 1993 & 85 & 77 & 1.10 & \\
\hline
\end{tabular}

a)

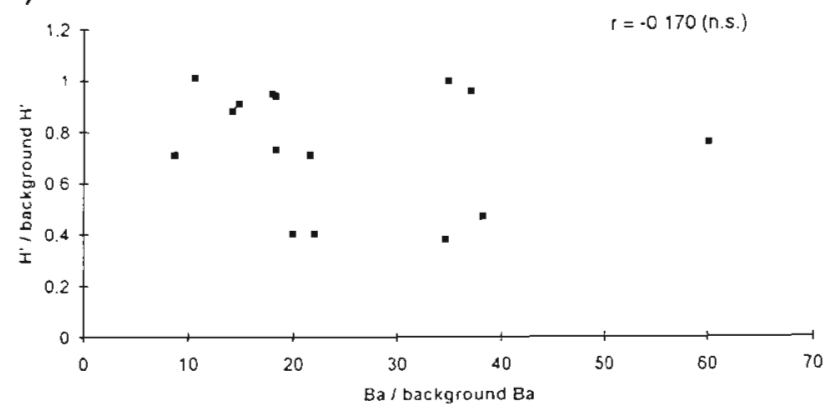

c)

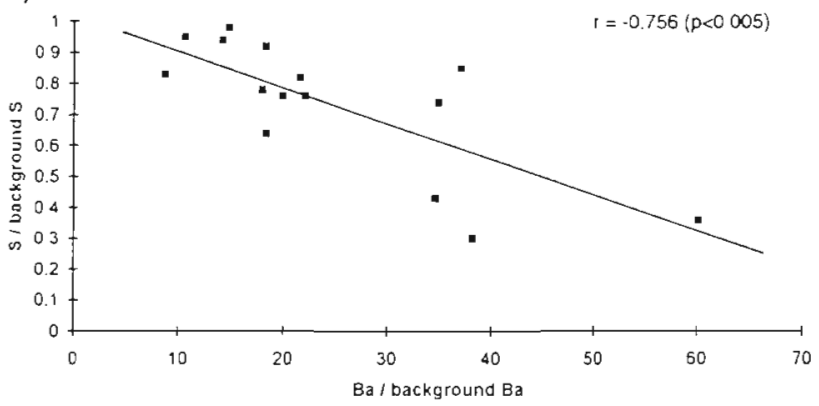

b)

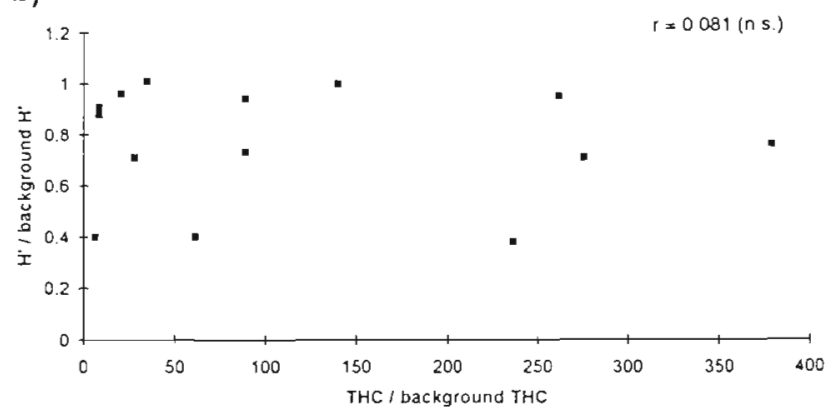

d)

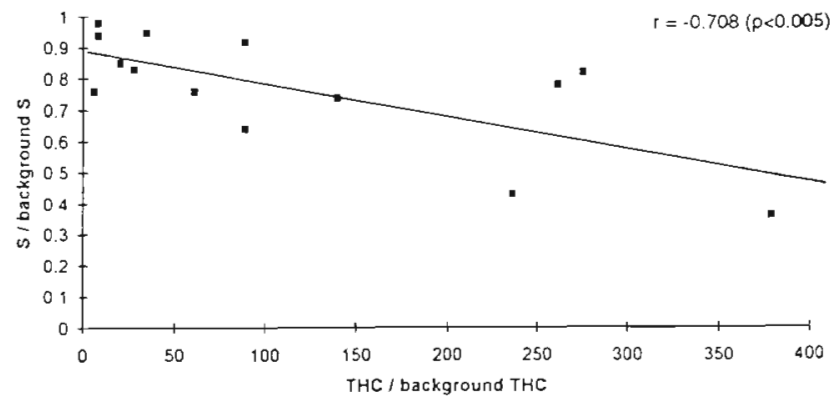

Fig. 15. Relationships between relative diversity (see text) against (a) relative values of barium, Ba and (b) relative values of total hydrocarbons, THC; and relationship between relative number of species and relative values of (c) Ba and (d) THC. The resulting correlation coefficients ( $\mathrm{r}$ ) from linear regression analysis are also given, with level of significance. Only the regressions in (c) and (d) were statistically significant $(p<0.05)$ and hence the regression lines (solid) are given for these 2 plots 
amination. This is in agreement with Olsgard (1993) that changes in species richness are often a simpler and better parameter than e.g. Shannon-Wiener diversity index in assessing disturbance in benthic communities.

The results in Fig. 15 suggest that clear changes in diversity occur only at approximately 20 times background levels of Ba and 50 times background levels of THC. Gray et al. (1990) and Warwick \& Clarke (1992) have illustrated similar findings for the lack of sensitivity of changes in pattern of diversity at the Ekofisk field. Thus reliance by monitoring programmes on interpretations based on patterns of diversity alone need to be abandoned. Furthermore, species identity is not taken into account and identity is needed for a full interpretation of the data (see below).

The fact that multivariate methods showed much more sensitive responses is shown in Fig. 16a, b where fauna group $b$ (the initial phase of effect), when compared to the unaffected group a, was characterised by a doubling of background levels of $\mathrm{Ba}$ at Valhall

\section{a)}

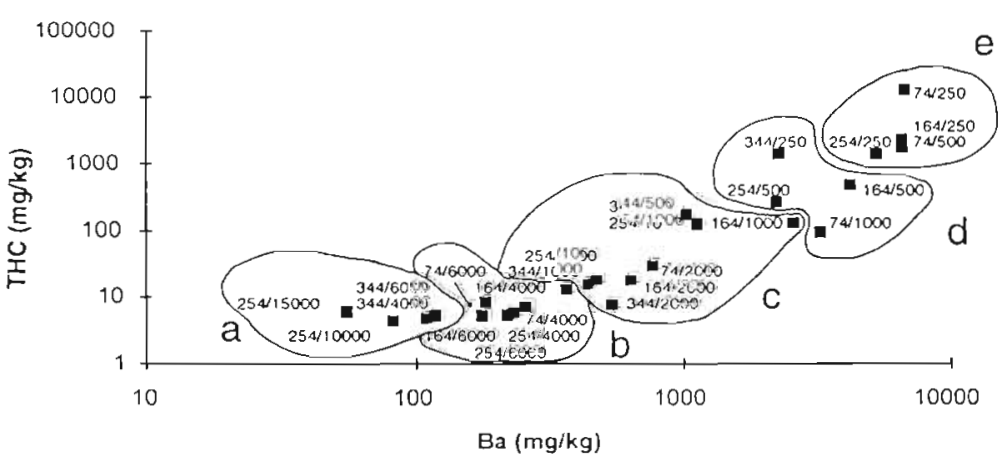

b)

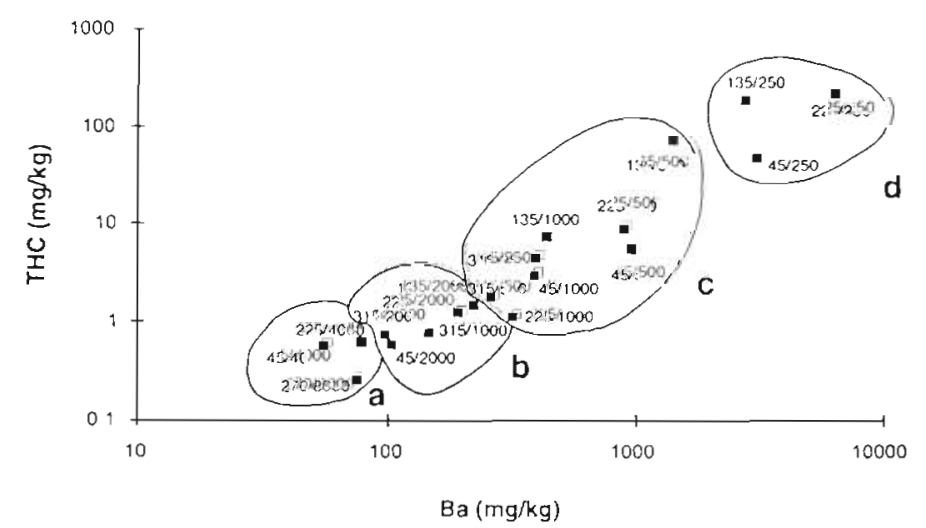

Fig. 16. Plots showing relationships between total hydrocarbons (THC) and barium $(\mathrm{Ba})$ in the sediments and the obtained taunal groupings from the multivariate analyses at (a) the Valhall field in 1991 and (b) the Gyda field in 1993
(Fig. 16a) and both Ba and THC at Gyda (Fig. 16b). Yet many chemical and physical variables, such as heavy metals and silt-clay fraction of the sediment, were intercorrelated with $\mathrm{THC}$ and $\mathrm{Ba}$.

Prior to the application of multivariate analyses methods, effects of oil-related discharges from platforms were generally believed to be found only within a 1 to $1.5 \mathrm{~km}$ radius. This was based on application of univariate statistical analysis tools to data such as the number of species and diversity indices (e.g. Addy et al. 1984, Davies et al. 1984, 1989, Mair et al. 1987, Kingston 1992, GESAMP 1993). In a comparison between species independent univariate and species dependent multivariate methods for analysing changes in benthic community structure, Warwick \& Clarke (1991) concluded that multivariate methods were much more sensitive in discriminating between stations or times.

Using multivariate analyses, Gray et al. (1990) were able to demonstrate clear effects to a radius of $3 \mathrm{~km}$ from the centre of the Ekofisk field in 1987. Thus the area affected was approximately $27 \mathrm{~km}^{2}$ compared with the accepted area of only $3 \mathrm{~km}^{2}$, which was mainly based on information from diversity indices. In this study we have shown clear contamination to areas of $>100 \mathrm{~km}^{2}$ at Valhall, $>15 \mathrm{~km}^{2}$ at Gyda and $>10 \mathrm{~km}^{2}$ at Veslefrikk with effects covering slightly smaller areas, $>60 \mathrm{~km}^{2},>12 \mathrm{~km}^{2}$ and $>9 \mathrm{~km}^{2}$, respectively. Pollution effects are thus found out to significantly greater distances than the accepted 1 to $1.5 \mathrm{~km}$ radius, suggested by Kingston (1992) in a recent review.

Addy et al. (1978) subjectively picked out species which to a large extent showed reduced abundance within 2 to $3 \mathrm{~km}$ from the Ekofisk oil-field and suggested this was related to discharges of oil from the platforms and to physical disturbance of the sediments. These species were the brittle star Amphiura filiformis and the 2 polychaetes Myriochele oculata and Owenia fusiformis. In our objective SIMPER analyses A. filiformis was also extracted as a sensitive species in this part of the North Sea (Table 7), while the 2 latter species in our study were ranked as sensitive species in fields further north (Table 7). Addy et al. (1978) also applied the Shannon-Wiener diversity index, but this did not lead to identification of the existing pollution gradient. In fact, due to an increased density of $M$. oculata mov- 
ing away from the platform a clear reduction in diversity with increased distance from the platforms emerged, again illustrating the lack of appropriateness of diversity indices for the assessment of effects of pollution on benthic communities.

The species that characterise the first stages of effects of pollution (Table 7 ) varied greatly over time and between fields. Between years at the same field there was little consistency, save perhaps for the polychaete Aonides paucibranchiata at the Statfjord field and Amphiura filiformis which characterised initial stages of effect at 4 and 5 different surveys, respectively. Gray et al. (1990) used identical methods to survey data from the Ekofisk field in 1987. Of the 15 species listed as characterising the initial stages of impact at Ekofisk only 3 (Myriochele oculata, Montacuta substriata and Ophiura affinis) occurred within the list of 32 species in Table 7 . This suggests that the pattern found in this study of no consistency either between years and/or fields is a general one, and that a search for 'universal' sensitive species is probably not worthwhile. This is not surprising since most of the species listed in Table 7 occurred in relatively low abundances and thus often changes in abundances recorded are small. The multivariate analyses are nevertheless sensitive to the patterns of increase and decrease of a relatively large number of species, and it is these changes that give discrimination between groups.

With severe pollution the characteristic species were more consistent between fields and times (Table 8). The typical indicators of severe effects around oil platforms were the polychaetes Capitella capitata, Chaetozone setosa, Cirratulus cirratus, Raricirrus berylli and the bivalve Thyasira sarsii. These species increased in abundance in the severely polluted zone at 5 surveys or more in different areas. In the Ekofisk analyses, Gray et al. (1990) found that $C$. capitata and C. setosa were the 2 most pollution tolerant species. $C$. capitata has been suggested as a 'universal indicator' of organic pollution (Reish 1973)

Gray (1982) suggested that what was needed were not indicators of end-points of severe pollution but rather indicators of the initial stages of pollution. The results from our study suggest that even within fairly discrete geographical areas there are no consistent patterns of sensitive 'indicator species' that can be suggested. There can be several reasons why the search for universal, sensitive indicator species is unfruitful. Firstly, there seem to be notable, natural differences in fauna composition within fairly restricted areas, probably due to minor differences in depth and sediment composition. Secondly, sensitive species are likely to be specific for 1 , or maybe 2 particular types of pollution as the organisms cannot be equally sensitive to all types of pollution (e.g organics, metals, oil, pesti-cides, etc.). Thirdly, an indi- cator species can be sensitive to one pollutant and tolerant to another. In a review of biotic indices based on tolerant and sensitive species, Washington (1984) stressed that such indices were necessarily limited to the geographical area in which the species lists are compiled. This being the case, reliance has rather to be placed on the application of statistical techniques, such as those used here to assess the patterns of change. The idea behind the use of indicators is that it might be possible to simplify assessments by concentrating only on these species in future surveys. Such a simplification does not seem realistic.

Another key question can be raised: Is it possible to distinguish between effects of physical disturbance, chemical toxicity and organic enrichment on the benthos? Gray (1982) suggested that rather than adapting to pollution by means of tolerance, many benthic species were more likely to be adapting to physical disturbance and that responses shown by species to organic enrichment were more likely to be a response to physical disturbance (sedimentation) than to tolerance of low oxygen. Olsgard \& Hasle (1993) supported Gray's hypothesis, showing that the responses of species to a purely physical pollutant (mine waste) were identical to that shown to organic enrichment (Pearson \& Rosenberg 1978), in that the total number of species was severely reduced, and a few opportunistic species increased greatly in abundance thereby increasing the total abundance. As a consequence of these changes, values of diversity indices decreased significantly. In contrast, where toxic effects often occur, often both the total number of species and the number of individuals decreases [e.g. response to a toxic alga (Olsgard 1993) or heavy metals (Rygg 1986)] and as a consequence the values of diversity indices did not usually decrease These findings suggest that it may be possible to separate impact resulting from physical effects/organic enrichment from toxic effects.

As shown above, diversity indices show varying responses depending on the type of pollutant. Since pollution gradients will often be composed of a mixture of physical/organic and toxic compounds it will not usually be possible to predict how diversity indices will respond. This can be illustrated from our data in that near the oil platforms there was no relationship between the concentration of known pollutants (e.g. $\mathrm{Ba}$ and THC) and diversity (Fig. 15a, b). At the stations with clearly elevated levels of $\mathrm{Ba}$ and $\mathrm{THC}$ chemical effects presumably dominated whereas at others physical effects dominated, hence there is no clear relationship between diversity and contaminant load. However, where there are clear gradients of a single, non-toxic factor a relationship between diversity and the dose can be shown (e.g. physical disturbance by sedimentation; Olsgard \& Hasle 1993). One must also 
bear in mind that diversity indices will be affected by natural factors, for example recruitment of large numbers of individuals will reduce the values of indices, and it is well-known that diversity indices are samplesize dependent. Interpretation of changes in values of diversity indices are therefore difficult. In contrast, using multivariate analyses, which are based on a detailed comparison of the totality of responses of all the species present in field samples, it is now possible to identify pollution effects at an early stage and, in addition, by comparing number of species and abundance it should be possible to separate the effects of physical effects/organic enrichment from chemical sources of pollution. Where toxic effects dominate the major response is likely to be a reduction in both numbers of species and abundance, without a significant increase in abundance of opportunistic species. Such findings must call into question the utility of using short-term toxicity tests on robust (often opportunistic) species as a means of predicting the likely environmental impact of discharging such chemicals.

Heip et al. (1988) and Warwick (1988a, b) have suggested that identification to the species level may not be necessary, as from cases related to organic and chemical pollution they were able to show that using the same data no information was lost by analysing the results at the family level. If such findings can be applied generally and consistently then considerable improvements can be made in survey efficiency, as it will be possible to take more samples for the same effort and thereby give better spatial coverage and statistical precision to the analyses. The data sets in this paper are appropriate for assessment of the utility of analyses based on higher taxal levels than the species and will be the subject of a further paper.

There has been considerable debate on whether or not the initial effects recorded here, of changes in benthic community structure, are important (Gray 1991. 1992, Holt 1992, Milne 1992). The Norwegian authorities reacted to the $27 \mathrm{~km}^{2}$ affected at Ekofisk (Gray et al. 1990), together with indications of similar effects at Statfjord (Reiersen et al. 1989), by saying that this was not predicted by Environmental Impact Assessments which claimed that only a $3 \mathrm{~km}^{2}$ area would be affected. They first legislated the amount of oil in cuttings that could be discharged to $6 \%$ in 1987 and then instituted a total ban on discharges of oil-based drillcuttings in January 1993. The oil-based drill-cuttings in the Norwegian sector are now occasionally reinjected down the bore hole, or brought ashore for disposal.

It is known that in the period 1984 to 1990 , in the British sector of the North Sea, the amount of oil-based drill-cuttings discharged was over 8 times that discharged in the Norwegian sector (PARCOM 1992).
Thus it is likely that a large area of the sea-bed of the North Sea is contaminated and will show effects on the benthic fauna.

In the context of importance of these effects one question that is often raised is what is the wider significance of finding effects on benthos for fish or the food for fish. Our data for the Valhall and Gyda fields showed that one of the significant effects was that the densities of the brittle star Amphiura filiformis decreased from mean values of 80 to 160 ind. $\mathrm{m}^{-2}$ in the uncontaminated areas to means of 10 to 40 ind. $\mathrm{m}^{-2}$ in the initially affected areas and were almost absent closer than 1 to $2 \mathrm{~km}$ from the platforms. The ventilatory activities of this brittle star improve the oxygenation of the sediment which subsequently affects the total benthic respiration, mineralisation and distribution of other fauna (Ockelman \& Muus 1978).

Amphiura filiformis is known to be eaten by Gadidae

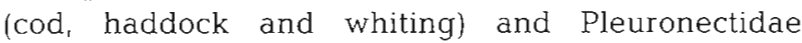
(plaice, witch, dab and sole) in Norwegian coastal areas (Pethon 1989), the North Sea (Duineveld \& Van Noort 1986), the Kattegat (Blegvad 1930, Pihl 1994) and the Irish Sea (Jones 1952). The study of Jones (1952) showed that $A$. filiformis in fact was the main food item of plaice, dab and sole in these waters, and Pihl (1994) found that this brittle star was the main prey of plaice and dab in the Kattegat. A. filiformis is a dominant member of the community and is a key member controlling structure and probably function of the benthic communities studied (Duineveld \& Van Noort 1986). The fauna in the highly contaminated areas is dominated by small polychaetes which are subsurface living. It is unlikely that such fauna are as valuable as an undisturbed community with a wider range of both sizes of organisms and modes of life. There is therefore emerging evidence that the effects which are now found to cover large areas of sea-bed could potentially have negative effect on fish.

Acknowledgements. We thank M. I. Abdullah and T Bakke for comments, J. R. Hasle and 3 anonymous reviewers for most helpful comments and suggested changes which greatly improved the manuscript. A large amount of data have emerged from offshore chemical and biological monitonng of the Norwegian continental shelf. This is a result of work which has been carried out by the various consultants, institutions and oil companies to comply with Norwegian regulations. Only due to their efforts was the study presented here possible. The reports prepared by the following consultants, institutions and oil companies (in alphabetical order) are gratefully acknowledged: Akvaplan, Akvaplan-Niva, Amoco, BP, DNV Industry, ERT, FSC, George, Hedeselskapet, IKU, IOE, Lindesnes Biolab, NAC, NGU, NIVA, Norsk Hydro, Oceanor, OPRU, Saga, Seas, SI, SINTEF, SINTEF-SI, Statoil, TKS, UiB, UiO, UiT, Unilab, Veritas Miljøplan. Parts of this study were supported by a grant to J.S.G. from the Norwegian Research Council for the engagement of F.O., which is gratefully acknowledged. 


\section{LITERATURE CITED}

Addy JM, Levell D, Hartley JP (1978) Biological monitoring of sediments in the Ekofisk oilfield. In: Proceedings of the conference on assessment of ecological impacts of oil spills. Am Inst Biol Sci, Keystone, CO, p 514-539

Addy JM, Hartley JP, Tibbetts PJC (1984) Ecological effects of low toxicity oil-based mud drilling in the Beatrice oilfield. Mar Pollut Bull 15:429-436

Anon (1989) Guidelines for monitoring methods to be used in the vicinity of platforms in the North Sea. Paris Commission, p $1-28$

Anon (1990) Manual for overvåkingsundersøkelser rundt petroleurnsinstallasjoner i norske områder. Statens Forurensningstilsyn (SFT) 90:01, p 1-29

Anon (1993) Utslipp av olje og kjemikaljer fra plattformene pđ̃ norsk kontinentalsokkel i 1992. Statens Forurensningstilsyn (SFT) 979/1993, p 1-32

Anon (1994) Oljedirektoratets-årsberetning 1993. Oljedirek. toratet, Oslo, p 1-164

Bakke T, Gray JS, Lichtenthaler RG, Palmork KH (1993) Miljøundersøkelser rundt petroleums-installasjoner på norsk kontinentalsokkel. Statens fourensningstilsyn (SFT), Oslo, p 1-92

Blegvad H (1930) Quantitative investigations of bottom invertebrates in the Kattegat with special reference to plaice food. Rep Dan biol Stn 36:3-56

Bray JR, Curtis JT (1957) An ordination of the upland forest communities of Southern Wisconsin. Ecol Monogr 27 $325-349$

Cabrera J (1971) Survival of the oyster Crassostrea virginica (Gmelin) in the laboratory under the effects of oil drilling fluids spilled in the Laguna de Tamiahua, Mexico. Gulf Res Rep 3:197-213

Clarke KR (1993) Non-parametric multivariate analyses of changes in community structure. Aust $J$ Ecol 18:117-143

Clarke KR, Ainsworth M (1993) A method of linking multivariate community structure to environmental variables. Mar Ecol Prog Ser 92:205-209

Davies JM, Addy J, Blackman R, Ferbache J, Moore D, Somerville $H$, Whitehead A, Wilkinson T (1984) Environmental effects of oil-based mud cuttings. Mar Pollut Bull $15: 363-370$

Davies JM, Bedborough DR, Blackman RAA, Addy JM, Appelbee JF, Grogan WC, Parker JG, Whitehead A (1989) Environmental effects of oil-based mud drilling in the North Sea. In: Engelhardt FR, Ray JP, Gillam AH (eds) Drilling wastes. Elsevier Applied Science, London, $\mathrm{p}$ $59-89$

Davies JM, Hardy R, McIntyre AD (1981) Environmental effects of North Sea oil operations. Mar Pollut Bull 12 : $412-416$

Davies JM, Kingston PF \{1992\} Sources of environmental disturbance associated with offshore oil and gas developments. In: Cairns WJ (ed) North Sea oil and the environment - developing oil and gas resources, environmental impacts and responses. International Council on Oil and the Environment, Elsevier, London, p 417-440

Dicks B, Bakke T, Dixon IMT (1987) Oil exploration and production impact on the North Sea. Oil Chem Poll 3:289-306

Dixon IMT (1987) Experimental application of oil-based muds and cuttings to seabed sediments. In: Kuiper J, Van den Brink WJ (eds) Fate and effects of oil in marine ecosystems. Martinus Nijkoff Publications, Dordrecht, p 133-150

Duineveld GCA, Van Noort GJ (1986) Observations of the population dynamics of Amphiura filiformis (Ophiuroidea:
Echinodermata) in the Southern North Sea and its exploitation by the dab, Limanda limanda. Neth J Sea Res $2085-94$

George RY (1975) Potential effects of oil drilling and dumping activities on marine biota. In: Environmental aspects of chemical use in well-drilling operations. Conference Proceedings, May 1975, Houston, Texas. Report No EPA-560/1-75-004, US Environmental Protection Agency, p 333-355

GESAMP (IMO/FAO/UNESCO/WMO/IAEA/UN/UNEP Joint Group of Experts on the Scientific Aspects of Marine Pollution) (1993) Impact of oil and related chemicals and wastes on the marine environment. GESAMP Rep Stud 50 $1-180$

Gray JS (1982) Effects of pollutants on marine ecosystems Neth J Sea Res 16:424-443

Gray JS (1991) Anthropocentric or ecocentric? Mar Pollut Bull 22:529

Gray JS (1992) Prof. Gray replies. Mar Pollut Bull 24:325

Gray JS, Clarke KR, Warwick RM, Hobbs G (1990) Detection of initial effects of pollution on marine benthos: an example from the Ekofisk and Eldfisk oilfields, North Sea. Mar Ecol Prog Ser 66:285-299

Green RH (1979) Sampling design and statistical methods for environmental biologists. Wiley, Chichester, p 1-257

Heip C, Basford D, Craeymeersch JA, Dewarumez JM, Dörjes $J$, de Wilde P. Duineveld G, Eleftheriou A, Herman PMJ, Niermann U, Kingston P, Künitzer A, Rachor E, Rumohr H, Soetaert K, Soltwedel T (1992) Trends in biomass, density and diversity of the North Sea macrofauna. ICES J mar Sci 49:13-22

Heip C, Warwick RM, Carr MR, Herman PMJ, Huys R, Smol N, Van Holsbeke K (1988) Analysis of community attributes of the benthic meiofauna of Frierfjord/Langesundsfjord Mar Ecol Prog Ser 46:171-180

Hill MO (1979) Decorana - a Fortran program for detrended correspondence analysis and reciprocal averaging. Cornell University, Ithaca, NY, p 1-52

Hill MO, Gauch HG (1980) Detrended correspondence analysis: an improved ordination technique. Vegetatio 42:47-48

Holt SJ (1992) Selfish altruism. Mar Pollut Bull 24:323-324

Jackson DA (1993) Multivariate analysis of benthic invertebrate communities: the implication of choosing particular data standardisations, measures of association and ordination methods. Hydrobiologia 268:9-26

Jones NS (1952) The bottom fauna and the food of flatfish off the Cumberland coast. J Anim Ecol 21:182-205

Kingston PF (1992) Impact of offshore oil production installations on the benthos of the North Sea. ICES J mar Sci 49 . $45-53$

Kruskal JB (1964a) Multidimensional scaling by optimizing goodness of fit to a non-metric hypothesis. Psychometrika 29:1-27

Kruskal JB (1964b) Nonmetric multidimensional scaling: a numeric method. Psychometrika 29:115-129

Kruskal JB, Wish M (1978) Multidimensional scaling. Sage Publishers, Beverly Hills, CA, p 1-93

Lance GN, Williams WT (1967) A general theory of classificatory sorting strategies. I. Hierarchical systems. Comp J 9 $373-380$

Levell D (1987) A summary of research and monitoring studies carried out in North Sea oilfields by the Oil Pollution Research Unit 1973-1986. In: Kuiper J, Van den Brink WJ (eds) Fate and effects of oil in marine ecosystems. Martinus Nijhoff Publishers, Dordrecht, p 295-330

Mair JMCD, Matheson I, Appelbee JF (1987) Offshore macrobenthic recovery in the Murchison field following termi- 
nation of drill cuttings discharge. Mar Pollut Bulj. 18: $628-634$

Minchun PR (1987) An evaluation of the relative robustness of techniques for ecological ordination. Vegetatio 67:89-107

Milne A (1992) Moderate astonishment. Mar Pollut Bull 24: $324-325$

Ockelman KW, Muus K (1978) The biology, ecology and behaviour of the bivalve Mysella bidentata (Montagu). Ophelia 17:1-93

Olsgard F (1993) Do toxic algal blooms affect subtidal softbottom communities? Mar Ecol Prog Ser 102:269-285

Olsgard F, Hasle JR (1993) Impact of waste from titanium mining on benthic fauna. J exp Mar Biol Ecol 172:185-213

PARCOM (1992) Discharges of oil in the convention area. Paris Commission, p 1-93

Pearson TH, Rosenberg R (1978) Macrobenthic succession in relation to organic enrichment and pollution of the marine environment. Oceanogr mar Biol A Rev 16:229-311

Pethon P (1989) Aschehougs store fiskebok. Aschehoug \& Co, Oslo, p $1-447$

Pihl L (1994) Changes in diet of demersal fish due to eutrophication-induced hypoxia in the Kattegat, Sweden. Can J Fish Aquat Sci 51:321-336

Reiersen LO, Gray JS, Palmork KH, Lange R (1989) Monitoring in the vicinity of oil and gas platforms: results from the Norwegian sector of the North Sea and recommended methods for forthcoming surveillance. In: Engelhardt FR, Ray JP, Gillam AH (eds) Drilling wastes. Elsevier Applied Science, London, p 91-117

Reish DJ (1973) The use of benthic animals in monitoring the marine environment. J envir Plann Pollut Contr 1:32-38

Rygg B (1986) Heavy metal pollution and log-normal distributions of individuals among species in benthic communities. Mar Pollut Bull 17:31-36

Shepard RN (1962) The analysis of proximities: multidimensional scaling with an unknown distance function. II. Psychometrika 27:219-246

This article was submitted to the editor
Smilauer P (1992) CANODRAW a companion program to CANOCO for publication-quality graphical output (version 3.0 LITE). Microcomputer Power, Ithaca, NY

Starczak VR, Fuller CM, Butman CA (1992) Effects of barite on aspects of ecology of the polychaete Mediomastus ambiseta. Mar Ecol Prog Ser 85:269-282

Støvring M (1994) North Sea zoobenthos - reported from the vicinity of oll platforms. In: Zetterberg $G$ (ed) Term list ZB North Sea zoobenthos, Version 930309-GUZ. Environmental Data Standardization, Term List 2. Nordic Code Centre \& Swedish Museum of Natural History

Tagatz ME, Tobia M (1978) Effect of barite $\left(\mathrm{BaSO}_{4}\right)$ on development of estuarine communities. Estuar coast mar Sci 7: 401-407

ter Braak CJF (1988) CANOCO - a Fortran program for canonical community o:dination by (partial) (detrended) (canonical) correspondence analysis, principal components analysis and redundance analysis (version 3.10). TNO Inst appl Comp Sci Stat Dept, p 1-95

ter Braak CJF (1990) Update notes: CANOCO version 3.10. Agricultural Mathematics Group, Wageningen

Warwick RM (1988a) Analysis of community attributes of the macrobenthos of Frierfjord/Langesundfjord at taxonomic levels higher than species. Mar Ecol Prog Ser $46: 167-170$

Warwick RM (1988b) The level of taxonomic discrimination required to detect pollution effects on marine benthic communities. Mar Pollut Bull 19:259-268

Warwick RM, Clarke KR (1991) A comparison of some methods for analysing changes in benthic community structure. J mar biol Ass UK 71:225-244

Warwick RM, Clarke KR (1992) Comparing the severity of disturbance: a meta-analysis of marine macrobenthic community data. Mar Ecol Prog Ser 92:221-231

Washington HG (1984) Diversity, biotic and similarity indices. A review with special relevance to aquatic systems. Water Res 18:653-694

Manuscript first received: Jilly 20,1994

Revised version accepted: January 13, 1995 